Aus der Abteilung Kieferorthopädie

(Prof. Dr. med. dent. D. Kubein-Meesenburg)

im Zentrum Zahn-, Mund- und Kieferheilkunde

der Medizinischen Fakultät der Universität Göttingen

\title{
Kraftabgabe thermoplastisch geformter Schienen mit inzisaler Schlitzung zur orthodontischen Zahnbewegung
}

\author{
INAUGURAL - DISSERTATION \\ zur Erlangung des Doktorgrades \\ für Zahnheilkunde \\ der Medizinischen Fakultät \\ der Georg-August-Universität zu Göttingen
}

vorgelegt von

Sarah-Alena Seiffert

aus

Göttingen

Göttingen 2012 
Dekan:

I. Berichterstatter:

II. Berichterstatter/in:

III. Berichterstatter/in:

Tag der mündlichen Prüfung: $\quad$ 14.08.2012
Prof. Dr. med. M. P. Schön

PD Dr. med. dent. W. Hahn

PD Dr. med. dent. N. Gersdorff 
Abkürzungsverzeichnis

$\begin{array}{ll}\text { Abb. } & \text { Abbildung } \\ \text { Anova } & \text { Analysis of variance (Varianzanalyse) } \\ \text { Bar } & \text { Gesetzliche Einheit für Druck } \\ \text { bzw. } & \text { Beziehungsweise } \\ { }^{\circ} \text { C } & \text { Grad Celsius } \\ \text { CAD } & \text { Computer Aided Design (Computer gestütztes Konstruieren) } \\ \text { CAM } & \text { Computer Aided Manufacturing (Computer unterstützte Fertigung) } \\ \text { D.h. } & \text { das heisst } \\ \text { F } & \text { Force (Symbol für die Kraft) } \\ \text { g } & \text { Gramm } \\ \text { k/Pa } & \text { Kilopascal } \\ \mu m & \text { Mikrometer } \\ \mathrm{ml} & \text { Milliliter } \\ \mathrm{mm} & \text { Millimeter } \\ \mathrm{N} & \text { Newton (Maßeinheit für die Kraft) } \\ \mathrm{N} / \mathrm{cm}{ }^{2} & \text { Newton pro Quadratzentimeter } \\ \mathrm{PET} & \text { Polyethylenterephthalat } \\ \mathrm{SD} & \text { Standardabweichung } \\ \mathrm{T} & \text { Torque (Symbol für das Drehmoment) } \\ \text { Tab. } & \text { Variable } \\ \text { Var. } & \text { zum Beispiel } \\ \text { z.B. } & \end{array}$




\section{Inhaltsverzeichnis}

$1 \quad$ Einleitung ....................................................................................................................................... 1

1.1 Historischer Überblick der orthodontischen Schienentherapie ................................... 1

1.2 Indikationen und Kontraindikationen thermoplastisch geformter Schienen zur Zahnbewegung

1.3 Therapeutische Zahnbewegung und biologische Nebenwirkungen ............................... 4

1.4 Biomechanische Grundlagen der Zahnbewegung ....................................................... 5

1.5 Biomechanik thermoplastisch geformter Schienen ............................................... 7

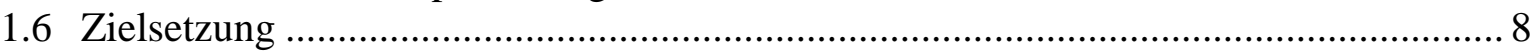

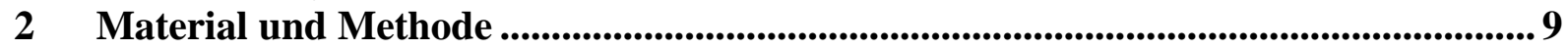

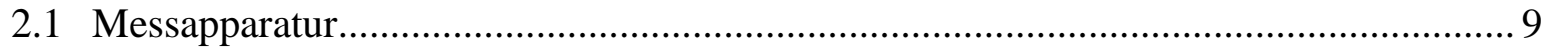

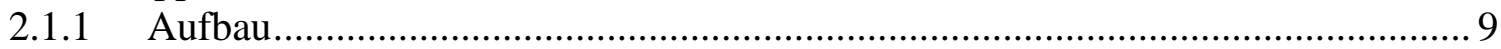

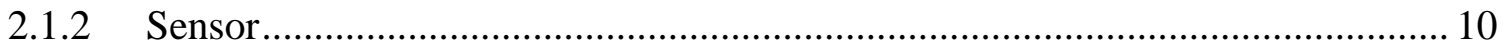

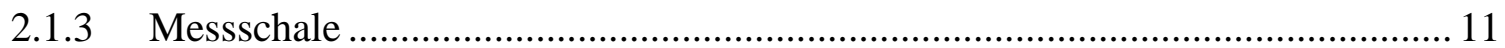

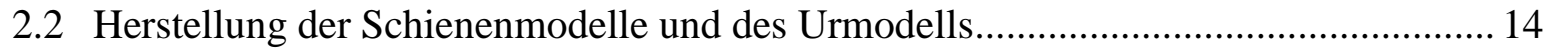

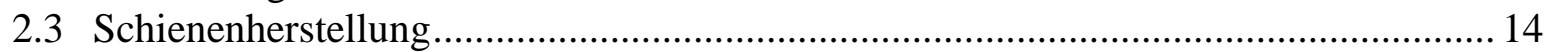

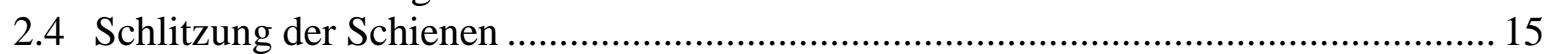

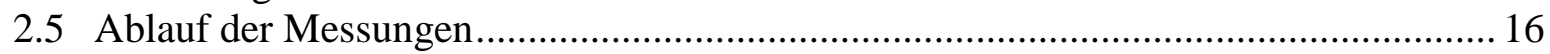

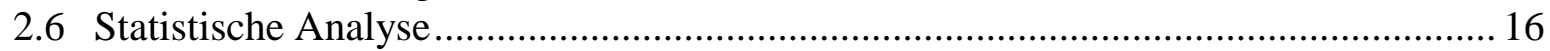

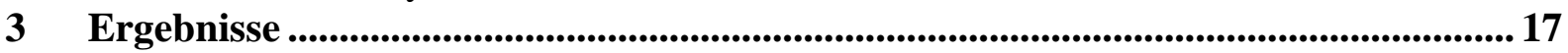

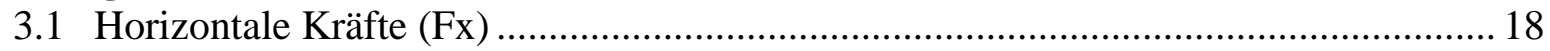

3.1.1 Horizontale Kräfte (Fx) ungeschlitzter Schienen ......................................... 18

3.1.2 Horizontale Kräfte (Fx) der am Zahn 11 geschlitzten Schienen......................... 19

3.1.3 Horizontale Kräfte (Fx) der an den Zähnen 12-21 geschlitzten Schienen .......... 20

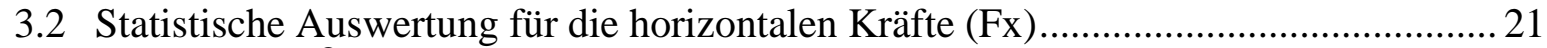

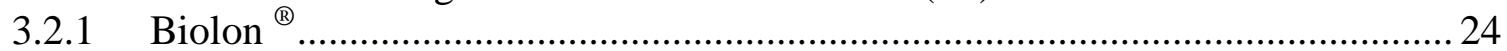

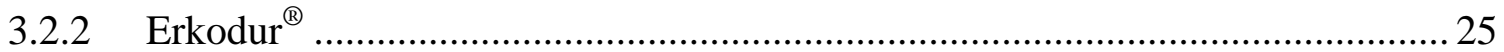

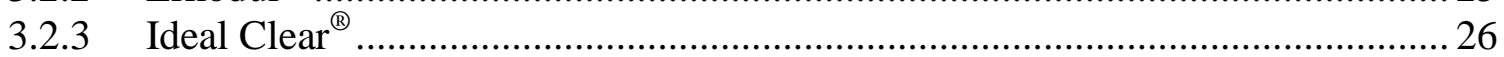

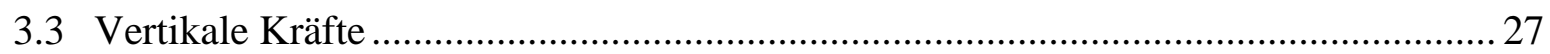

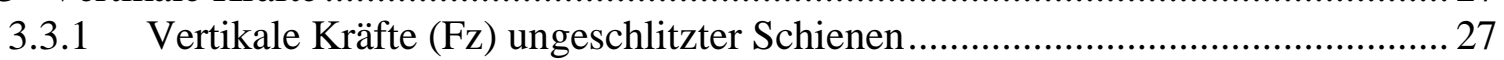

3.3.2 Vertikale Kräfte (Fz) der am Zahn 11 geschlitzten Schienen ............................. 28

3.3.3 Vertikale Kräfte (Fz) der an den Zähnen 12-21 geschlitzten Schienen ............... 29

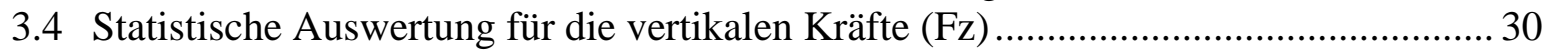

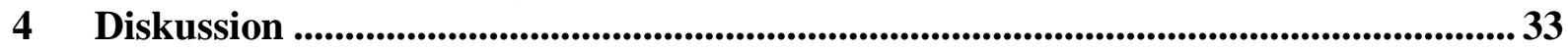

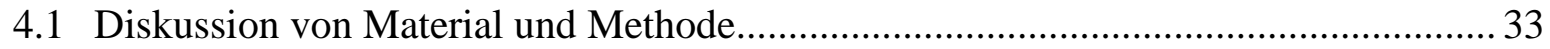

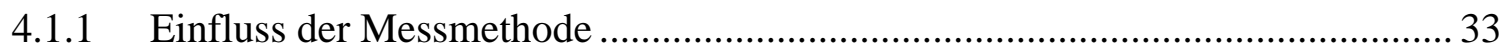

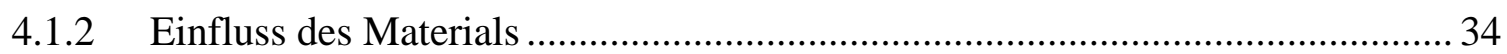

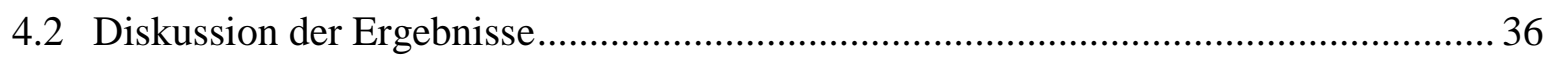

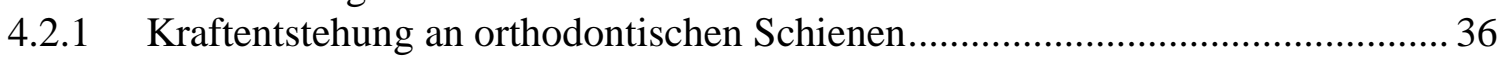

4.2.2 Betrachtung der Kraftabnahme mit Zunahme der Schlitzgröße ......................... 37

4.2.3 Betrachtung des Kraftrichtungswechsels von intrusiven zu extrusiven Kräften 38

4.2.4 Betrachtung der gemessenen Kräfte in Abhängigkeit der Kipprichtung ............ 41

4.2.5 Die klinische Bedeutung der gemessenen Kraftgrößen ..................................... 42

4.2.6 Vergleich mit Kraftmessungen an Schienen anderer Materialien und bei ............. anderen Bewegungsformen........................................................................ 44

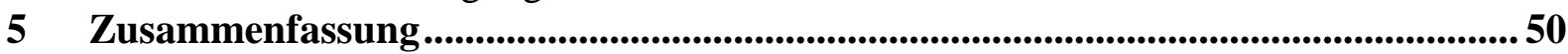

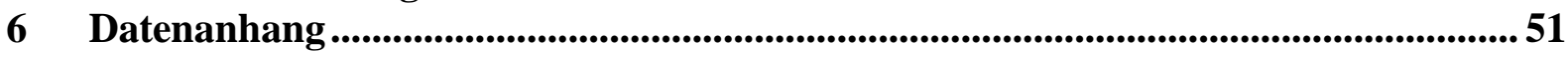

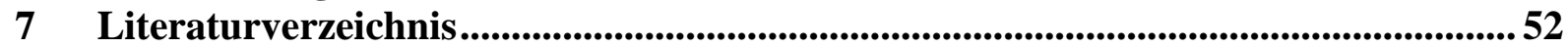




\section{$1 \quad$ Einleitung}

In vielen Gesellschaften wird heute viel Wert auf Schönheit und Ästhetik gelegt - dies hat auch Auswirkungen auf die Zahnmedizin. Viele Patienten sind unzufrieden mit ihrer Zahnstellung, wünschen sich jedoch zur Behandlung dieser Zahnfehlstellungen eine weniger sichtbare Alternative zur herkömmlichen festsitzenden kieferorthopädischen Behandlungsapparatur. Dieser Anspruch hat in den 1990er Jahren zur Entwicklung einer neuen Behandlungsmethode mit durchsichtigen, thermoplastisch geformten Schienen geführt (VLASKALIC et al. 2001).

Ziel der vorliegenden Studie ist es, die Kräfte zu ermitteln, die bei Kippung eines oberen mittleren Frontzahnes durch thermoplastisch geformte Schienen erzeugt werden, welche durch Schlitzung im Inzisalbereich modifiziert wurden.

\subsection{Historischer Überblick der orthodontischen Schienentherapie}

Seit Mitte der 1940er Jahre wird versucht, Zähne mit schienenartigen Behandlungsapparaturen $\mathrm{zu}$ bewegen. KESLING (1945) führte mit Positionern aus vulkanisiertem Kautschuk die Feineinstellung bzw. Retention der Zähne nach Multibandbehandlung durch. Des Weiteren beschrieb er die Behandlung mit elastischen schienenähnlichen Apparaturen unter Verwendung einer Reihe individuell hergestellter Modelle. In den folgenden Jahrzehnten publizierten daraufhin zahlreiche Autoren ähnliche Konzepte als Alternative zu festsitzenden Apparaturen (PONITZ 1971, SHERIDAN et al. 1993, RINCHUSE und RINCHUSE 1997, LINDAUER und SHOFF 1998, DJEU et al. 2005). Basierend auf dem „invisible retainer“ von PONITZ (1971) wurde Anfang der 1990er Jahre der EssixRetainer als komfortable und ästhetische Alternative $\mathrm{zu}$ herkömmlichen Retainern aus Kautschuk vorgestellt. Darüber hinaus konnte er als aktives Gerät zur Korrektur von kleineren Zahnfehlstellungen verwendet werden (SHERIDAN et al. 1993, RINCHUSE und RINCHUSE 1997). Auf Grundlage der Überlegungen von KESLING (1945) basiert das heutige Prinzip der Schienentherapie: Die aktuelle Zahnstellung des Patienten, also die Ist-Situation, wird mittels eines Gipsmodells erfasst. Anschließend werden die zu regulierenden Zähne in kleinen Teilschritten in Richtung Idealposition verstellt. Jeder Zwischenschritt wird in Form eines Modells festgehalten. Auf diesem wird schließlich eine Schiene aus Kunststoff gefertigt. Nach dem Einsetzen der jeweiligen Schiene kommt es, bedingt durch die abweichende Ist-Position 
der Zähne, zu einer elastischen Verformung des Kunststoffes, die als Rückstellkräfte auf die zu therapierenden Zähne wirkt. Dadurch sollen sich diese in die durch die Schiene vorgegebene neue Stellung bewegen.

Es lassen sich zwei Prinzipien unterscheiden, mit denen entsprechende Schienen hergestellt werden können: Bei dem einen (ClearSmile ${ }^{\circledR}$-System, Woollongong, Australia) erfolgt die Umstellung der Zähne klassisch manuell auf einem Gipsmodell (BARBAGALLO et al. 2008a), bei dem anderen (Invisalign ${ }^{\circledR}$-System, Align Technologies Inc., Santa Clara, CA, USA) liegt der Hauptunterschied zur konventionellen Schienentherapie in der verwendeten CAD/CAMTechnologie (Vlaskalic et al. 2001, GiAnCOTTI et al. 2006). Dabei werden zur Herstellung der individuellen Schienen ein Bissregistrat und eine Abformung mit einem additionsvernetzten Silikon benötigt. Die hergestellten Gipsmodelle werden mit Hilfe eines Laserscanners digitalisiert. Mittels einer speziellen Software („ClinCheck“-Software) ist es möglich, virtuelle Zahnbewegungen durchzuführen und somit einen Behandlungsplan zu erstellen. Korrekturen des behandelnden Zahnarztes können via Internet vorgenommen werden (VLASKALIC et al. 2001, GiANCOTTI et al. 2006). Als Basis für die Schienen werden im Anschluss zunächst für jedes Behandlungsstadium stereolithographische Kunststoffmodelle produziert. Die benötigten Schienen werden aus einem thermoplastischen Kunststoff mit Hilfe von Biostar ${ }^{\circledR}$-Geräten (Scheu Dental Technology, Iserlohn, Germany) tiefgezogen (WONG 2002). Die für die Schienen verwendeten Materialien sind systemspezifisch und bestehen aus Polyethylen, Polyurethan oder Polypropylen und können Dicken zwischen 0,7 mm (FALTIN et al. 2003) und $1 \mathrm{~mm}$ aufweisen (SHERIDAN et al. 1993). Die Behandlungsdauer einer durchschnittlichen Therapie beträgt fünfzig Wochen, in der fünfundzwanzig Aligner verwendet werden. Patientenabhängig kann die Anzahl der eingegliederten Schienen zwischen zehn und fünfzig variieren. Wird die empfohlene Tragedauer von mindestens zwanzig Stunden pro Tag eingehalten, kann nach jeweils zwei Wochen ein neuer Aligner eingesetzt werden (JOFFE 2003). Es lassen sich in den bereits veröffentlichten Studien unterschiedliche Angaben bezüglich der möglichen Zahnbewegungsstrecke finden. Einige Autoren sprechen von 0,15 mm bis 0,25 mm (VLASKALIC et al. 2001, FALTIN et al. 2003, GiANCOTTI et al. 2006), andere von 0,25 mm bis 0,33 mm (Boyd et al. 2000, OwEN 2001) oder 0,25 $\mathrm{mm}$ bis $0,30 \mathrm{~mm}$ (JOFFE 2003). 


\subsection{Indikationen und Kontraindikationen thermoplastisch geformter Schienen zur Zahnbewegung}

Thermoplastisch geformte Schienen für minimale Zahnkorrekturen werden heute als Alternative zu festsitzenden Apparaturen bei der Behandlung von Erwachsenen oder Jugendlichen (LAGRAVÈre und Flores-MIR 2005, Nedwed und MiethKe 2005, BARBAGallo et al. 2008a) mit einem bereits vollständigen bleibenden Gebiss verwendet (VLASKALIC et al. 2001). Diese Therapie wird insbesondere von weiblichen Patienten im Alter von Anfang bis Ende zwanzig in Anspruch genommen (MEIER et al. 2003, NEDWED und MiETHKE 2005).

Minimale Zahnfehlstellungen, leichte Zahnbogenexpansionen, die Korrektur eines tiefen Überbisses sowie Platzprobleme von 1-5 mm werden als Indikationsbereiche für die Schienentherapie angegeben (JOFFE 2003). Neben der verbesserten Ästhetik und der einfacheren Handhabung durch den Patienten sind ebenfalls der erhöhte Tragekomfort, die gute Mundhygienemöglichkeit sowie eine verkürzte Stuhlzeit als Hauptvorteile gegenüber der konventionellen Behandlung mit festsitzenden Apparaturen zu nennen (JOFFE 2003, VlASKALIC et al. 2001). Des Weiteren ist meist eine uneingeschränkte Sprachbildung möglich (Vlaskalic et al. 2001). Die Vorteile der Schienentherapie werden auch durch die Studie von NeDwed und MiethKe (2005) untermauert. Sie untersuchten die Akzeptanz, Motivation und Probleme von Patienten während der Behandlung mit Invisalign ${ }^{\circledR}$. Den Ergebnissen zufolge waren 89\% der Studienteilnehmer mit dem erzielten Behandlungserfolg zufrieden.

Die Korrektur von stark rotierten Zähnen über $20^{\circ}$, von skelettalen Diskrepanzen von mehr als $2 \mathrm{~mm}$, von Extrusion und Zähnen mit kurzen klinischen Kronen sowie Molarendistalisation von mehr als $2 \mathrm{~mm}$ und die Behandlung eines offenen Bisses hingegen stellen ein Problem dar (VLASKALIC und BOYD 2001, JOFFE 2003). Intermaxilläre Korrekturen sind ebenfalls nicht alleine mit thermoplastisch geformten Schienen zu therapieren. Auch Torquebewegungen mit dem Ziel einer vorhersagbaren Wurzelposition lassen sich mit Schienen nur eingeschränkt realisieren (JOFFE 2003). BREZNIAK (2008) und HAHN et al. (2010b) stellten fest, dass mit Schienen eine körperliche Zahnbewegung nur schlecht möglich ist. Dies führten sie darauf zurück, dass die Schienen okklusal Kraft auf den Zahn ausübten. Da sich die Schiene bei der Insertion deformierte und sich im gingivalen Bereich der Rand vom Zahn wegbewegte, konnte das zur körperlichen Zahnbewegung benötigte Kräftepaar nicht entstehen. Die okklusal erzeugte Kraft bewirkte eine kippende und intrusive Bewegung (BREZNIAK 2008). 
KRAVITZ et al. (2008) untersuchten in ihrer aktuellen Studie die Rotationsmöglichkeit von Eckzähnen mit Invisalign ${ }^{\circledR}$, wobei nur in $35,8 \%$ der Fälle eine erfolgreiche Behandlung verzeichnet werden konnte. Damit wird die Schwierigkeit, Derotationen von Eckzähnen und Prämolaren mit Schienen durchzuführen, bestätigt. Dieses Ergebnis hängt mit der ungünstigen Zahnmorphologie und dem begrenzten Kraftansatz der Aligner-Schienen zusammen. Durch zusätzliche Attachments (z.B. lingual/bukkal bzw. labial platzierte Kompositaufbauten oder Knöpfe) ist die Wahrscheinlichkeit einer dreidimensionalen kontrollierten Zahnbewegung gegeben. Die Derotation von Frontzähnen stellt hingegen eine der Hauptindikationen dar (GöZ 2010).

\subsection{Therapeutische Zahnbewegung und biologische Nebenwirkungen}

Die zur orthodontischen Zahnbewegung verwendete optimale Kraftgröße wurde von verschiedenen Autoren diskutiert. Überwiegend wurde die Auffassung vertreten, dass die Anwendung geringer Kräfte von Vorteil wäre, um biologische Schäden zu vermeiden (SCHWARZ 1931, OPPENHEIM 1942, REITAN 1967, FARRAR 1876). In anderen Studien hingegen wurde die Forderung nach größeren Kräften laut (HIXON et al. 1970, ANDREASEN und ZWANZIGER 1980). Nach Dorow und SANDER (2005) sollten Kräfte eine Bewegung mit größtmöglicher Geschwindigkeit bewirken, aber zugleich keine Schäden am Parodontium, dem Alveolarknochen oder dem Zahn selbst verursachen. Eine Kraft wird demzufolge dann als ideal angesehen, wenn sie in der Lage ist, eine maximale Zahnbewegung mit minimaler Schädigung des Gewebes zu erzielen. Laut PROFFIT (2000) liegt der optimale Kraftbereich für Intrusion zwischen 0,1 $\mathrm{N}$ und 0,2 $\mathrm{N}$ und für Kippbewegungen zwischen 0,35 $\mathrm{N}$ und 0,6 $\mathrm{N}$.

In der Literatur werden kontinuierliche, intermittierende und unterbrochene Kräfte unterschieden: Herausnehmbare Geräte erzeugen intermittierende Kräfte. Unterbrochene und kontinuierliche Kräfte lassen sich durch festsitzende Apparaturen bewirken. Die kontinuierliche Kraft unterscheidet sich von der unterbrochenen Kraft dadurch, dass sie zwischen den einzelnen Aktivierungen nicht bis auf den Nullpunkt absinkt (PROFFIT 2000).

Neben der Größe wurden auch Kraftdauer und Frequenz der Kraft untersucht. Zum Einen wurde die Meinung vertreten, dass kontinuierliche Kräfte besser für die Zahnbewegung seien, weil ein geringeres Risiko für Wurzelresorptionen besteht (SCHWARZ 1932, PROFFIT 2000, KWON et al. 2008). 
Andere Autoren postulierten, dass kontinuierliche Kräfte ungeeignet sind, um kieferorthopädischen Gewebeumbau zu induzieren (HäUPL 1938) oder sie sprachen sich gegen kontinuierliche Kräfte aus, da sie unerwünschte Nebenwirkungen wie Wurzelresorptionen oder Nekrosen (Hyalinisation) fanden (MALTHA et al. 2004).

Einige Autoren führten Faktoren wie beispielsweise $\mathrm{zu}$ große Kräfte als Ursache für Nebenwirkungen an (Hotz 1967, Maltha et al. 1995, OwMAN-Moll et al. 1996, Faltin et al. 1998, OwMAN-Moll und Kurol 1998, PARKer und Harris 1998, ACAR et al. 1999, CASA et al. 2001, SAmeshima und Sinclair 2001, Harris et al. 2006, Apajalahti und Peltola 2007), während andere biologische Faktoren (z. B. genetische Prädisposition, Habits oder Alter) als Ursache für Nebenwirkungen nannten (LEVANDER und MALMGREN 1988, FALTIN et al. 1998, OwMAN-Moll und Kurol 2000). Das Ausmaß der Resorption ist, unabhängig von den genannten Faktoren, individuell sehr unterschiedlich (MALTHA et al. 1993) und wird von verschiedenen Faktoren, wie z. B. Behandlungsdauer, Bewegungsausmaß (Göz und RAKOSI 1989) und anatomischen Gegebenheiten, beeinflusst.

\subsection{Biomechanische Grundlagen der Zahnbewegung}

Bewegungen von Körpern werden durch Kräfte bewirkt (SCHMUTH 1992). Die Richtung und Größe einer Kraft wird dabei durch einen Vektor dargestellt (KAHL-NIEKE 2001). Um die stattfindende Zahnbewegung aus einem applizierten Kraftsystem heraus vorherzusagen, stellen die einwirkende Kraft, das Widerstandszentrum, der Kraftansatzpunkt und schließlich das Rotationszentrum die relevanten Faktoren dar (SCHOPF 2000).

Diese sollen nun kurz erläutert werden. Das Widerstandszentrum ist definiert als der Punkt, an dem eine einzelne Kraft eine Translationsbewegung bewirkt (BURSTONE und PRYPUTNIEWICZ 1980). Die Lage des Widerstandszentrums eines Zahnes ist abhängig von der Wurzelform, -länge und -anzahl, der Attachmenthöhe, sowie der Morphologie des Bindegewebes und des Parodontiums (KAHL-NIEKE 2001). Bei einwurzeligen Zähnen liegt das Widerstandszentrum ungefähr am Übergang vom zervikalen zum mittleren Wurzeldrittel, bei mehrwurzligen Zähnen interradikulär und somit 1-2 mm apikal der Furkation (BURSTONE und PRYPUTNIEWICZ 1981).

Das Rotationszentrum ist definitionsgemäß der Punkt, um den sich ein Zahn dreht, wenn an einer beliebigen Stelle ein Drehmoment und/oder eine Kraft appliziert werden (HuRD und NiKOLAI 1976). Die Lage des Rotationszentrums ist wiederum abhängig vom 
Kraftangriffspunkt (KAHL-NIEKE 2001).Aufgrund anatomischer Gegebenheiten setzen Kräfte, die mittels kieferorthopädischer Apparaturen appliziert wurden, grundsätzlich im Bereich der Zahnkrone an und können nicht direkt durch das Widerstandszentrum laufen (KRÄMER 2010). Das Produkt aus Kraft und senkrechtem Abstand zum Widerstandszentrum wird als Drehmoment bezeichnet. Diese Art Drehmoment wird auch immanentes Drehmoment genannt, weil es jedem Kraftansatz, der an der Zahnkrone ansetzt, innewohnt (KAHL-NIEKE 2001). Ein Drehmoment kann auch durch zwei gleich große, aber in unterschiedliche Richtungen wirkende Kräfte, ein sogenanntes Kräftepaar, erzeugt werden. Ist das immanente Drehmoment nicht erwünscht, kann es durch ein Gegendrehmoment, das sogenannte therapeutische Drehmoment, ausgeglichen werden. Mit dem Quotienten aus Drehmoment und Kraft lässt sich ein Kraftsystem individualisieren und somit eine Bewegung kontrollieren (HARZER 1999).

Ein Zahn wird durch die Aufhängung im Parodontium als ein starrer, gestützter Körper angesehen (SCHMUTH 1992). Da ein entsprechender Körper durch Kraftapplikation seine Form beibehält, bewegt er sich. Dabei sind folgende Bewegungsformen möglich: Translation (körperliche Bewegung), Rotation (die Drehung um die eigenen Achse), Kippbewegung und Wurzelbewegung (KAHL-NIEKE 2001).

Jede Kraft, deren Wirkungslinie nicht direkt durch das Widerstandzentrum läuft, verursacht neben einer translatorischen auch eine rotatorische Komponente (SCHOPF 2000). Je näher der Kraftansatzpunkt am Widerstandszentrum liegt, desto höher ist der translatorische Anteil der Bewegung. Für eine reine Rotationsbewegung werden zwei gleich große Kräfte mit gegenläufigem, aber parallelem Kraftangriff benötigt, ein sogenanntes Kräftepaar (HARZER 1999).

Bei der Kippbewegung muss zwischen unkontrollierter und kontrollierter Kippung unterschieden werden. Für beide Bewegungsformen liegt der Kraftansatzpunkt okklusal vom Widerstandszentrum, jedoch mit unterschiedlichem Abstand. Das Rotationszentrum liegt dagegen apikal vom Widerstandszentrum. Die Krone bewegt sich dabei in Kraftrichtung, die Wurzel dagegen in die entgegengesetzte Richtung (KAHL-NIEKE 2001). Um eine Wurzelbewegung (Torque) zu bewirken, muss der Kraftangriffspunkt demnach apikal vom Widerstandzentrum liegen. Das Rotationszentrum befindet sich im koronalen Bereich des Zahnes (SCHOPF 2000). Es ist dabei relevant $\mathrm{zu}$ beachten, dass das therapeutische Drehmoment größer gewählt werden muss als das immanente Drehmoment (KAHL-NIEKE 2001). 
Aus den Kapiteln 1.3 und 1.4 lässt sich ableiten, dass es Ziel einer jeden kieferorthopädischen Apparatur sein muss, eine Kraft auf den zu bewegenden Zahn zu applizieren, die eine kontrollierte Bewegung in Bezug auf die Bewegungsrichtung und die Bewegungsgeschwindigkeit erlaubt und dabei zugleich das Risiko für unerwünschte Nebenwirkungen maximal reduziert.

\subsection{Biomechanik thermoplastisch geformter Schienen}

In der Literatur lassen sich bis heute nur wenige Studien finden, die sich mit der Kraftabgabe von thermoplastisch geformten Schienen beschäftigen.

WARUNEK et al. (1989) und RosT et al. (1995) analysierten in ihren in-vitro Untersuchungen die Kräfte, die Positioner an einem oberen mittleren Frontzahn mit unterschiedlich starker Protrusion abgaben. In einer weiteren in-vivo-Studie wurden die Kräfte gemessen, die an einer Schiene bei der Kippung eines Oberkieferprämolaren nach vestibulär zu Behandlungsbeginn und -ende auftraten. Dabei wurden neben horizontalen Kräften erstmalig auch intrusive Kräfte gemessen (BARBAGALLO et al. 2008b). KWON et al. (2008) ermittelten mittels eines 3-Punkt-Biegeversuches die Kraftabtgabe verschiedener Schienenmaterialien an flachen Probekörpern.

Durch das Einsetzen der thermoplastischen Apparatur kommt es zu einer elastischen Verformung des Aligners, wodurch eine Rückstellkraft auf den zu therapierenden Zahn wirkt (HAHN 2009). Eine systematische Untersuchung der dabei entstehenden Kräfte wurde erstmals im Rahmen einer Studienserie, zu der auch die vorliegende Untersuchung gehört, durchgeführt. Dabei wurden die Kräfte ermittelt, die bei unterschiedlichen Bewegungsformen (Kippung, Torque und Rotation) des ersten oberen Schneidezahnes mit unterschiedlichen Schienenmaterialien erzeugt wurden (ENGELKE 2010, HAHN 2009, HAHN et al. 2009a, HAHN et al. 2009b, HAHN et al. 2010a, HAHN et al. 2010b, HAHN et al. 2011).

Bei den bisherigen Untersuchungen zur Kraftabgabe thermoplastisch geformter Schienen wurden schon bei geringen Auslenkungsstrecken des zu bewegenden Zahnes sehr hohe Kräfte gemessen (ENGELKE 2010, HAHN 2009, HAHN et al. 2009a, HAHN et al. 2009b, HAHN et al. 2010a, HAHN et al. 2010b, HAHN et al. 2011). Daneben wurde im Rahmen dieser Studienserie erstmals auch eine intrusive Kraft bei allen Bewegungsformen mit thermoplastischen Schienen nachgewiesen und quantifiziert. Dabei wurden Schienen untersucht, die keine 
weitere Modifikation zur Beeinflussung der abgegebenen Kräfte am Schienenkörper aufwiesen.

\subsection{Zielsetzung}

Ziel der vorliegenden Arbeit ist es, die Kräfte zu ermitteln, die von modifizierten Schienen bei Kippung eines oberen mittleren Schneidezahnes erzeugt wurden. Als Gegenstand der Untersuchung dienten dabei Schienen aus drei verschiedenen Materialien. Die Modifikation des Schienenkörpers bestand dabei in unterschiedlich weit ausgedehnten Schlitzungen im Bereich der Inzisalkante. 


\section{Material und Methode}

\subsection{Messapparatur}

\subsubsection{Aufbau}

Zur Messung der durch die Schienen abgegebenen Kräfte wurde eine modulare Messapparatur zur Kraft-Drehmoment-Messung kieferorthopädischer Apparaturen verwendet. Diese Apparatur wurde speziell zu diesem Zweck in Kooperation mit den wissenschaftlichen Werkstätten der UMG entwickelt und gebaut. Die verwendete modulare Messapparatur besteht aus einem quadratischen Rahmen aus Hartaluminium und einer Basisplatte, die über vier Säulen miteinander verbunden sind. In den Metallrahmen wird eine Kunststoffschale positioniert, die mittels einer Klemmschraube reversibel in gleicher Position fixierbar ist. In der Kunststoffschale ist ein standardisiertes Kunststoffmodell der Oberkieferzahnreihe eines fünfzehn- bis zwanzigjährigen männlichen Patienten (Frasaco GmbH, Tettnang, Germany) mit Gips befestigt. Zentral unterhalb der Kunststoffschale befindet sich der verwendete Sensor, der mit dem im Modell beweglich fixierten Messzahn verbunden ist. Der Sensor selbst ist auf einem Präzisionsstelltisch verschraubt, der wiederum über unterschiedliche Gestelle auf der Grundplatte montiert ist (Abb. 1a).

Für die Erzeugung der Kippbewegung wurde ein Goniometer (GO 90-W30, OWIS GmbH, Staufen, Germany) verwendet. Um die Erfassung der Kräfte bei Körpertemperatur von $37^{\circ} \mathrm{C}$ zu simulieren, wird die gesamte Einheit mit einem Thermoschrank Typ HTD 50 (Flohr Instruments, Utrecht, Holland) verbunden. Am Boden des Thermoschrankes befindet sich eine Öffnung, an welche sich die modulare Messeinheit mittels eines Drehtisches (DT 130; OWIS GmbH, Staufen, Germany) heranführen lässt (Abb. 1b). 

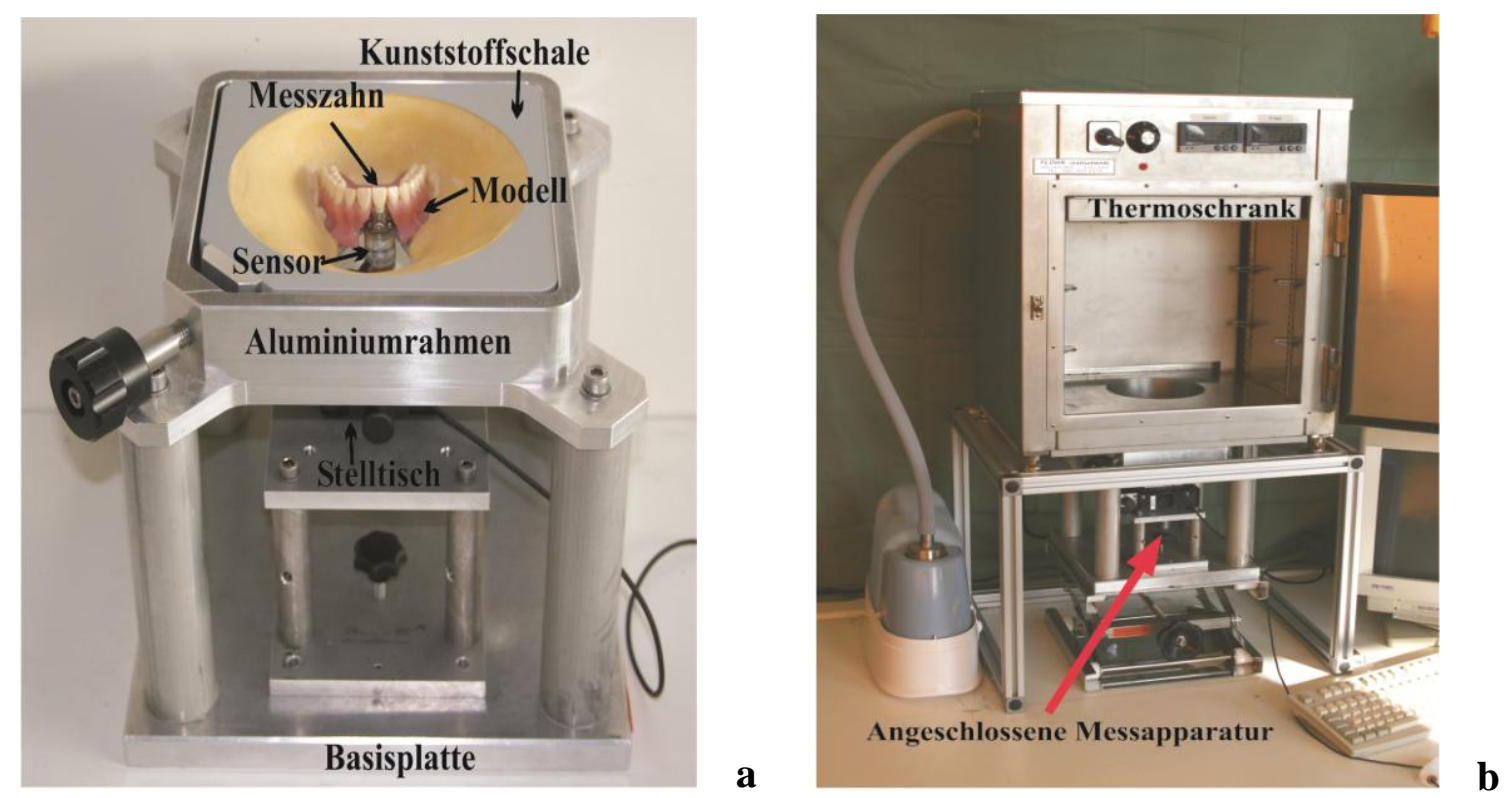

Abbildung 1a: Darstellung der modularen Messapparatur (HAHN 2009, S.9).

Abbildung 1b: Darstellung des komplexen Versuchsaufbaus in der Frontansicht. Die modulare Messapparatur wurde mittels eines Hubtisches unter den Thermoschrank gebracht (HAHN 2009, S.9).

\subsubsection{Sensor}

Bei dem verwendeten Sensor handelt es sich um einen Nano 17 Sensor (ATI Industrial Automation, Apex, USA) (Abb. 2a) zur Ermittlung von Kräften (Fx, Fy, Fz) und Drehmomenten (Tx, Ty, Tz). Diese lassen sich für alle Ebenen des Raumes getrennt aufschlüsseln (Abb. 2b). Der Sensor besteht aus drei Messsträngen. Die Einzelstränge weisen zwei Halbleiter-Dehnungsmessbrücken auf, die eine Verformung im Mikrometerbereich erkennen. Er wird durch das Sensorkabel mit der Spannungsversorgungsbox mit integriertem Verstärkerboard verbunden. Diese steht wiederum über ein Verbindungskabel mit einem Computer in Kontakt (http://www.schunk.com/schunk_files/attachments/FT-Nano_17_DE.pdf). 

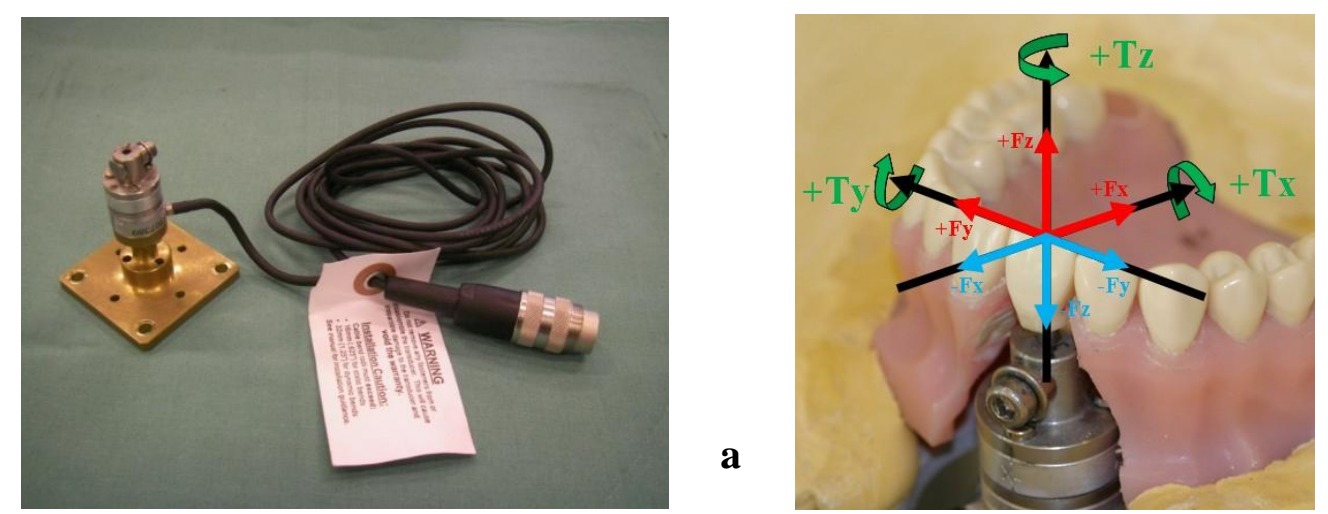

b

Abbildung 2a: Nano 17 Sensor auf Montageplatte mit aufgeschraubter Klemmvorrichtung zur Aufnahme des Messzahnes (ATI Industrial Automation, Apex, USA).

Abbildung 2b: Wirkungsrichtung der Kräfte und Drehmomente. Die negativen Drehmomente laufen gegenläufig zu den eingezeichneten positiven Drehmomenten (grüne Pfeile) (HAHN 2009, S.12).

\subsubsection{Messschale}

Im Zentrum der Messschale befindet sich das Zahnkranzmodell (Frasaco GmbH, Tettnang, Deutschland). Vor der Befestigung des Modells mit Superhartgips (GC Fujirock ${ }^{\circledR}$ EP, GC GERMANY GmbH, München, Deutschland) wurde der Messzahn aus der Zahnreihe herausgeschraubt und für die Studie individualisiert. Der Sockelbereich, also die künstliche Alveole, wurde mittels einer Fräse herausgetrennt. Diese Öffnung in der Schale ermöglicht die Verbindung zwischen Messzahn und Sensor (Abb. 3).

Um während des Aufbaus der Messapparatur den beweglichen Messzahn stets in der gleichen Position fixieren $\mathrm{zu}$ können, wurde vor dem Heraustrennen aus der Zahnreihe ein Gipsschlüssel (GC Fujirock ${ }^{\circledR}$ EP, GC GERMANY GmbH, München, Deutschland) hergestellt (Abb. 4b).

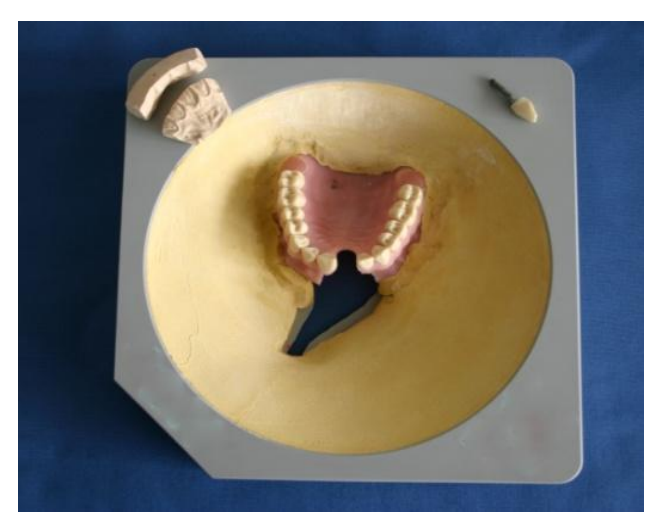

Abbildung 3: Messteller mit Messzahn und Repositionierungsschlüssel. 

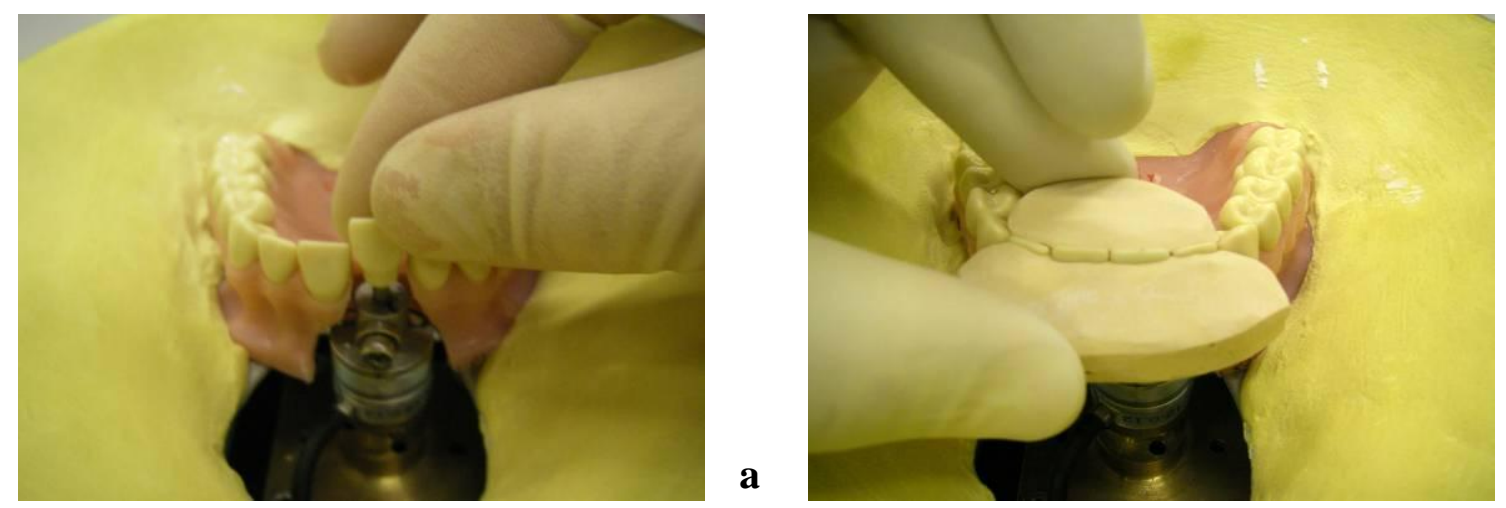

b

Abbildung 4a: Einsetzen des Messzahnes in die Klemmvorrichtung am Sensor.

Abbildung 4b: Reproduzierbare Positionierung des Messzahnes mittels Gipsschlüssel vor Arretierung am Sensor (ENGELKE 2010, S. 17).

Bei der Individualisierung des Messzahnes wurde die Zahnwurzel bis auf $1 \mathrm{~mm}$ unterhalb der bukkalen Schmelz-Zement-Grenze gekürzt. Anschließend erfolgte die optische Ausmessung des Wurzelbereichs und der Inzisalkante, um dort die jeweiligen geometrischen Zentren zu bestimmen. Die zentralen Punkte wurden daraufhin mittels eines feinen Diamantbohrers markiert, um die korrekte Justierung des Messzahnes in einer Zentrierungsapparatur zu gewährleisten. Diese besteht aus zwei Halbschalen, die zusammengefügt eine Hohlform ergeben. Die eine Hälfte hat an der Ober- und an der Unterseite jeweils eine regulierbare Zentrierungsspitze, die die Positionierung des Zahnes in der Mitte der Hohlform ermöglicht. Durch Vorschrauben der Zentrierungsspitzen bis $\mathrm{zu}$ den Markierungsstellen wird die Rotationsachse des Zahnes starr befestigt, womit die exakte Reproduzierbarkeit der Zahnposition gewährleistet ist (Abb. 5).

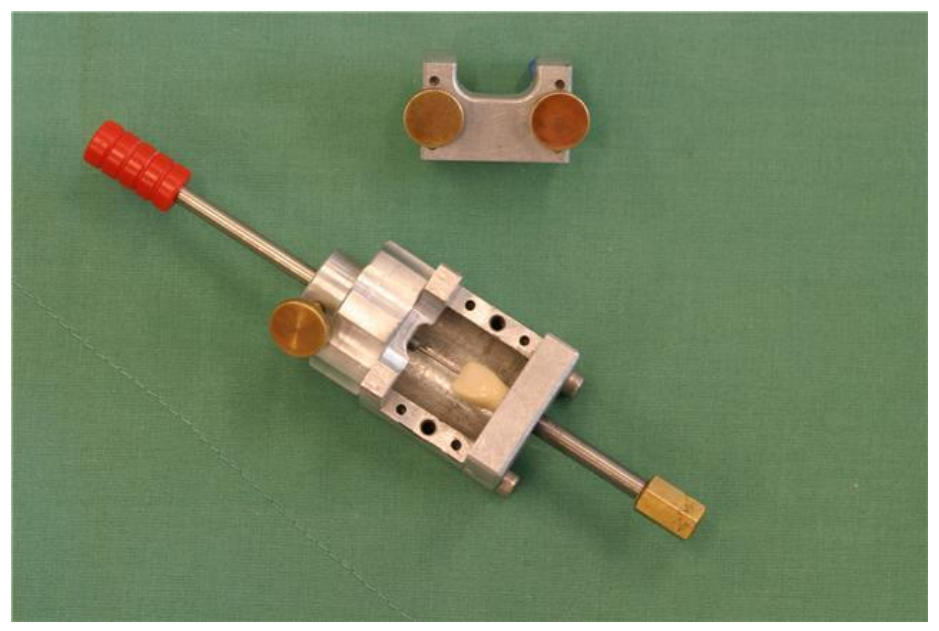

Abbildung 5: Zerlegte Zentrierungsapparatur mit eingespanntem Messzahn (ENGELKE 2010, S.11). 
Nach der Befestigung des Zahnes wurden die Halbschalen durch Schrauben miteinander verbunden. Der in der daraus entstandenen Hohlform verankerte Zahn wurde mit Gips (GC Fujirock $^{\circledR}$ EP, GC GERMANY GmbH, München, Deutschland) umgossen. Nachdem der Gips seine endgültige Härte erreicht hatte, wurde die Verschraubung gelöst und die entstandene Gipsform entnommen. Der Gipszylinder wurde im Anschluss achsenzentrisch mit Hilfe eines Dreibackenfutters in eine Präzisionsdrehbank (Condor, Weiler Werkzeugmaschinen, Emskirchen, Deutschland) eingeschraubt (Abb. 6). Mittels eines HSSSpiralbohrers (Ø 2,5 mm) wurde eine Normbohrung an der Unterseite des Zahnes angelegt. In die Bohröffnung wurde als Ersatz für die Wurzel ein Spiralbohrer mittels eines Kunststoffes (Weitur ${ }^{\circledR}$ Press, Johannes Weithas Dental-Kunststoffe, Lütjenburg, Deutschland) einpolymerisiert. Um eine Verdrehung zu vermeiden, wurde der Schaft des Spiralbohrers zuvor gekerbt.

Um einen Überlastungsschutz des Sensors zu gewährleisten, sollten unter Last möglichst geringe Drehmomente erzeugt werden, weshalb die Kürzung des Stiftes bis auf $1 \mathrm{~mm}$ Abstand zwischen Zahn und Sensor erfolgte. Die vollständige Länge von Metallstift und Zahn misst 24,4 mm.

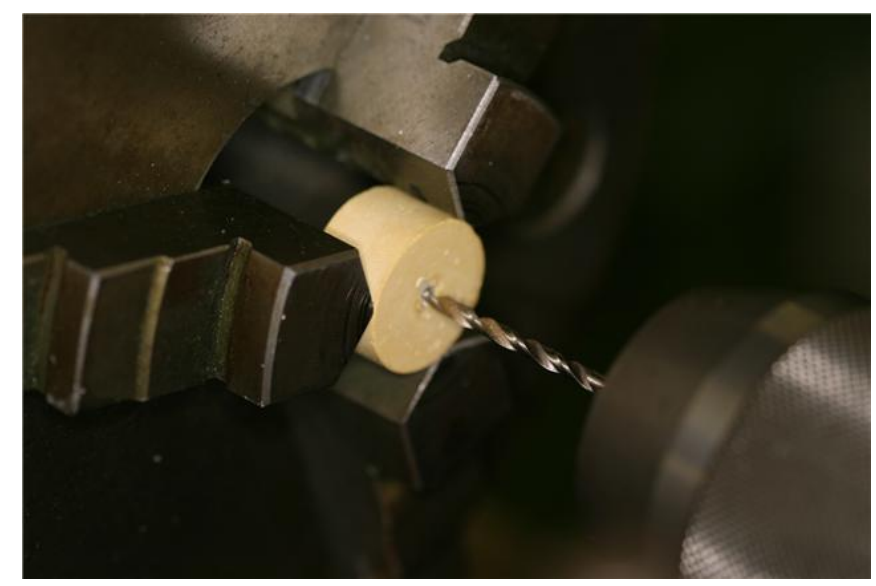

Abbildung 6: Anlegen der Normbohrung an der Unterseite des in Gips fixierten Messzahnes (ENGELKE 2010, S.12). 


\subsection{Herstellung der Schienenmodelle und des Urmodells}

Um eine vergleichbare Ausgangssituation für die zu messenden Schienen zu schaffen, wurde zunächst ein Urmodell aus Gips hergestellt. Hierbei entsprach die Position des Zahnes 11 der Nullposition ohne Kippung. Das Urmodell diente als Vorlage für alle weiteren Gipsmodelle, die zur Herstellung der thermoplastisch geformten Schienen verwendet wurden.

Für die Erstellung des Urmodells erfolgte zunächst ein Abdruck des für die Studie verwendeten Untersuchungsmodells mit Rim-Lock-Löffel und Alginat (Tetrachrom der Firma Kanidenta, Herford, Deutschland) an der aufgebauten Messapparatur. Die Abformung wurde mit GC Fujirock ${ }^{\circledR}$ EP (GC Germany GmbH, München, Germany; Mischverhältnis20 ml/100 g) ausgegossen.

Der entstandene Zahnkranz wurde auf eine Höhe von $20 \mathrm{~mm}$ parallel zur Okklusionsebene getrimmt (SHERIDAN et al. 2003), sämtliche untersichgehende Bereiche wurden mit einem Handstïck und einer Fräse entfernt.

Um weitere dem Urmodell identische Schienenmodelle herstellen zu können, erfolgte die Erstellung einer Dublierform aus Adisil ${ }^{\circledR}$ blau 9:1 (Siladent Dr. Böhme \& Schöps GmbH, Goslar, Deutschland). Zur Verbesserung der Benetzbarkeit der Silikonform fand vor dem Ausgießen mit Gips eine Vorbehandlung mit Waxit ${ }^{\circledR}$ (DeguDent GmbH, Hanau-Wolfgang, Deutschland) statt. Der weitere Herstellungsprozess der Gipsmodelle entspricht dem Ablauf für die Herstellung des Urmodells.

\subsection{Schienenherstellung}

Die Schienen bestehen aus modifiziertem Polyethylenterephthalat (PET). Dieser durch Polykondensation gewonnene thermoplastische Kunststoff zählt zur Stofffamilie der Polyester. Drei verschiedene Materialien von $1 \mathrm{~mm}$ Stärke wurden für die Schienenherstellung verwendet: Biolon ${ }^{\circledR}$ (Dreve Dentamid GmbH, Unna, Deutschland), Erkodur $^{\circledR}$ (Erkodent ${ }^{\circledR}$ Erich Kopp GmbH, Pfalzgrafenweiler, Deutschland) sowie Ideal Clear ${ }^{\circledR}$ (Dentsply GAC, Gräfelfing, Deutschland). Insgesamt wurden fünfundvierzig Schienen gefertigt. Aus jedem Material erfolgte die Herstellung von jeweils fünfzehn Schienen. Für den Tiefziehprozess der Schienen aus Biolon ${ }^{\circledR}$ wurde der Drufomat-TE (Dreve Dentamid GmbH, Unna, Deutschland) verwendet. Für die Schienen aus Ideal Clear ${ }^{\circledR}$ kam die „Vacuum Forming Machine“ Modelnr.: 202 (Dentsply GAC, Gräfelfing, Deutschland) zum Einsatz, für die 
Schiene aus Erkodur $^{\circledR}$ wurde der Erkoform RVE (Erkodent ${ }^{\circledR}$ Erich Kopp GmbH, Pfalzgrafenweiler, Deutschland) verwendet. Bei dem Drufomat-TE handelt es sich um ein Druck-Tiefziehgerät, die anderen beiden sind Vakuum-Geräte.

Nach dem Tiefziehprozess erfolgten die Ausarbeitung und die Anpassung des Schienenrandes an den Verlauf der marginalen Gingiva mittels HSS-Spiralbohrern und Lisko-SPolierscheiben (Erkodent ${ }^{\circledR}$ Erich Kopp GmbH, Pfalzgrafenweiler, Deutschland).

\subsection{Schlitzung der Schienen}

Für die Messung kamen fünfzehn Schienen ohne Schlitzung zur Anwendung, bei fünfzehn Schienen wurde ausschließlich die Inzisalkante des Messzahnes 11 freigelegt. Bei fünfzehn weiteren Schienen wurden die Nachbarzähne 12 und 21 mit einbezogen, sodass ein barrierefreier Schlitz von distal 12 bis distal $21 \mathrm{zu}$ erkennen war (Abb. 7). Damit die Schlitzung bei allen Schienen nahezu identisch war, wurden zuvor die Länge und Tiefe des Schlitzes mit einem Lineal und einem Farbstift markiert. Das Schlitzen erfolgte mit HSS Spiralbohrern und Lisko-S Polierscheiben (Erkodent ${ }^{\circledR}$ Erich Kopp GmbH, Pfalzgrafenweiler, Deutschland).

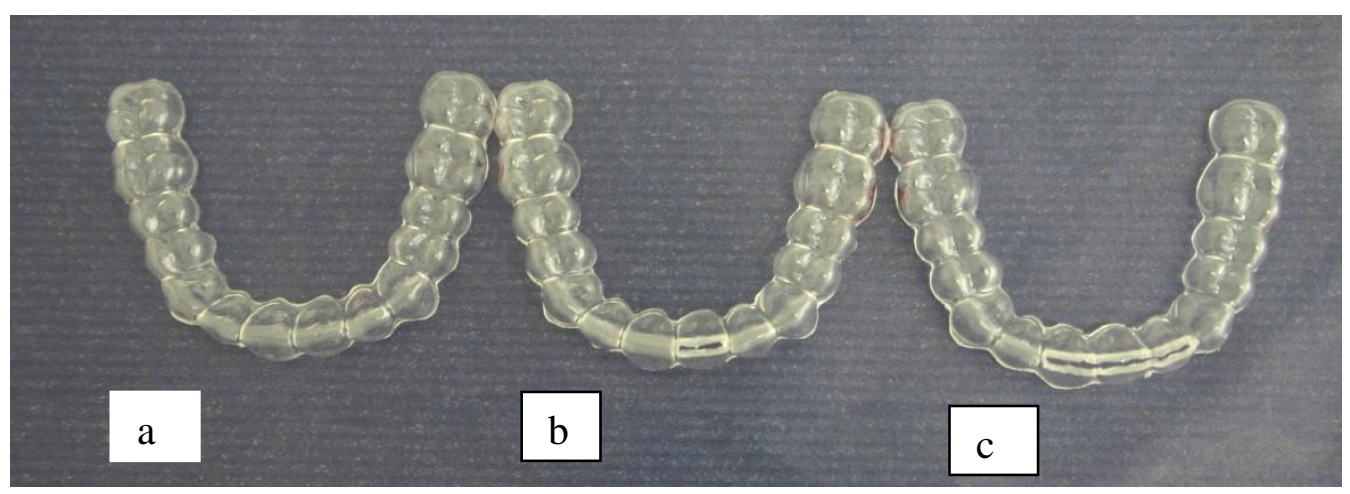

Abbildung 7: a) eine intakte Schiene, b) eine inzisal am Zahn 11 reduzierte Schiene, c) eine inzisal der Zähne 12-21 reduzierte Schiene. 


\subsection{Ablauf der Messungen}

Nach dem Aufbau der Messapparatur mit Positionierung des Messzahnes 11 in Nullposition erfolgte die Messung aller Schienen in gleicher Weise. Zunächst fand die Messung der ungeschlitzten Schienen aller drei Materialien statt, daraufhin die am Zahn 11 geschlitzten und abschließend die an den Zähnen 12-21 geschlitzten Schienen.

$\mathrm{Zu}$ Beginn einer jeden Messung wurde die Schiene mit (zwei Sprühstößen) künstlichem Speichel (Universitätsklinikumsapotheke, Göttingen, Deutschland) benetzt und auf das Untersuchungsmodell aufgesetzt. Der Präzisionsstelltisch und der Messzahn befanden sich dabei in Nullposition. Die beim Aufsetzen der Schiene entstandenen Kräfte und Drehmomente wurden vor Beginn des Messvorgangs über die DAQ F/T-Software auf null gestellt. Anschließend erfolgte die Kippung des Zahnes ausgehend von der Nullposition in 0,019 mm Einheiten in vestibulärer Richtung bis zur maximalen Auslenkung von 0,151 mm und von dort in gleichen Abständen zurück zur Nullposition. Die Strecke $\pm 0,151 \mathrm{~mm}$ entspricht dem geringsten in der Literatur angegebenen Aktivierungsschritt für die orthodontische Zahnbewegung mit thermoplastischen Schienen (BOYD und VLASKALIC 2001), deshalb wurde nur sie für die weitere Auswertung verwendet.

Mittels der DAQ F/T-Software wurden die entstandenen Kräfte und Drehmomente jedes einzelnen Messschrittes fünfmal nacheinander gespeichert. Nachdem dieser Messvorgang mit allen fünf Schienen einer Schlitzung und eines Materials durchgeführt wurde, konnte erneut mit der eingangs gemessenen Schiene begonnen werden. Der Messzahn wurde im nächsten Durchlauf nach palatinal gekippt wie zuvor für die vestibuläre Richtung beschrieben.

\subsection{Statistische Analyse}

Die Messergebnisse wurden im Tabellenkalkulationsprogramm Microsoft Office Excel/2007 tabellarisch erfasst. Die statische Analyse erfolgte mit dem Statistikprogramm SAS ${ }^{\circledR}$-software (SAS Institute Inc., Cary, NC/USA). Die Daten wurden mit einer mehrfaktoriellen gemischten Varianzanalyse (ANOVA) mit Messwiederholungen ausgewertet. Da keine Normalverteilung vorlag, wurden die Ränge der Beobachtungen verwendet. Das Signifikanzniveau wurde mit alpha $=0,05$ festgelegt. 


\section{$3 \quad$ Ergebnisse}

Mit der beschriebenen Messapparatur konnten die Werte für die Kräfte Fx, Fy und Fz sowie die korrespondierenden Drehmomente Tx, Ty Tz erfasst werden. Für die nachfolgende Diskussion werden jedoch ausschließlich die klinisch maßgeblich relevanten und in der Literatur im Wesentlichen beschriebenen Kräfte Fx (kippende Kraft) und Fz (intrusive Kraft) herangezogen. Aus diesem Grund erfolgte die Auswertung für diese beiden Parameter isoliert. Die graphische Darstellung der Ergebnisse erfolgte mit Box-Whisker-Plots und mit Hilfe von Tabellen.

Das positive (vestibuläre Auslenkung) oder negative (palatinale Auslenkung) Vorzeichen der Strecke gibt die Bewegungsrichtung an. Da bei den Messergebnissen durch die Vorzeichen nur die Wirkungsrichtung der Kraft angeben wird (Abb. 2b) und nicht die Kraftgröße, werden diese in der Auswertung bei der Ermittlung des arithmetischen Mittels nur für die vertikalen Kräfte (Fz) berücksichtigt, jedoch nicht für die horizontalen Kräfte (Fx).

Der Messzahn wurde in Teilschritten von $0^{\prime}$ bis 22,2' (Bogenminuten) nach vestibulär $\left(+22,2^{\prime}\right)$ und palatinal $\left(-22,2^{\prime}\right)$ ausgelenkt. Bei der Messung der einzelnen Schienen wurden bei jedem Winkel fünf Messwiederholungen aufgezeichnet. Hierbei ergaben sich typische Messkurven für die horizontalen (Fx) und vertikalen $\mathrm{Kräfte}(\mathrm{Fz})$, wie beispielhaft in Abbildung 8 für Fx und das Material Biolon ${ }^{\circledR} 1 \mathrm{~mm}$ dargestellt ist. Zur Ermittlung der Werte für die Grafik wurde der Mittelwert von allen aufgezeichneten Werten gebildet. 


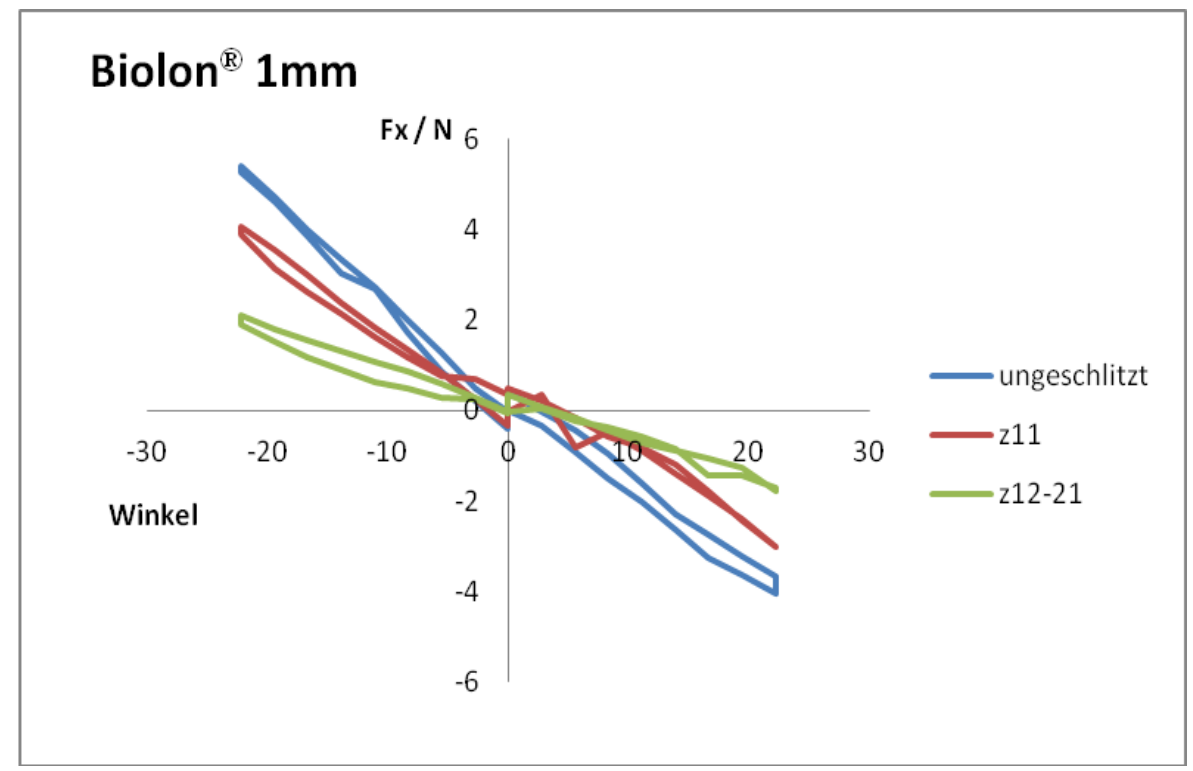

Abbildung 8: Die gemessenen horizontalen Kräfte (Fx) bei den entsprechenden Winkeln für das Material Biolon ${ }^{\circledR}$ getrennt für die ungeschlitzten, die am Zahn 11 und an den Zähnen 12-21 geschlitzten Schiene. Die y-Achse stellt die einzelnen Winkel und die x-Achse die gemessenen Kräfte dar (siehe auch Tab. 12, S. 51).

\subsection{Horizontale Kräfte (Fx)}

\subsubsection{Horizontale Kräfte (Fx) ungeschlitzter Schienen}

Der höchste Wert der horizontalen Kräfte bei ungeschlitzten Schienen wurde unabhängig von der Kipprichtung für Biolon ${ }^{\circledR}$ gemessen. Der niedrigste Wert wurde bei palatinaler Auslenkung für Erkodur ${ }^{\circledR}$ ermittelt und bei vestibulärer Kippung für Ideal Clear ${ }^{\circledR}$.

Die Mittelwerte bei palatinaler Auslenkung liegen zwischen 2,56 N (SD 0,56 N) und 4,03 N (SD 0,36 N). Die Werte bei vestibulärer Auslenkung betragen zwischen 3,10 N (SD 0,23 N) und 5,41 N (SD 0,80 N) (Tab. 1). 


\begin{tabular}{|c|c|c|c|c|c|c|c|}
\hline Strecke & Materialstärke & Material & Schlitzung & $\mathrm{N}$ & Var. & Mittelwert (N) & $\mathrm{SD}(\mathrm{N})$ \\
\hline \multirow{3}{*}{$\begin{array}{l}-0,151 \mathrm{~mm} \text { pal. } \\
\text { Kippung }\end{array}$} & $1 \mathrm{~mm}$ & Biolon ${ }^{\circledR}$ & Ohne & 5 & Fx & 4,03 & 0,36 \\
\hline & $1 \mathrm{~mm}$ & Erkodur $^{\circledR}$ & Ohne & 5 & Fx & 2,56 & 0,57 \\
\hline & $1 \mathrm{~mm}$ & IdealClear $^{\circledR}$ & Ohne & 5 & Fx & 2,91 & 0,42 \\
\hline \multirow{3}{*}{$\begin{array}{l}+0,151 \mathrm{~mm} \text { vest. } \\
\text { Kippung }\end{array}$} & $1 \mathrm{~mm}$ & Biolon $^{\circledR}$ & Ohne & 5 & Fx & 5,41 & 0,74 \\
\hline & $1 \mathrm{~mm}$ & Erkodur $^{\circledR}$ & Ohne & 5 & $\mathrm{Fx}$ & 3,11 & 0,23 \\
\hline & $1 \mathrm{~mm}$ & IdealClear $^{\circledR}$ & Ohne & 5 & Fx & 3,05 & 0,80 \\
\hline
\end{tabular}

Tabelle 1: Mittelwerte und Standardabweichung der horizontalen Kräfte (Fx) für die ungeschlitzten Schienen bei palatinaler und vestibulärer Auslenkung $( \pm 0,151 \mathrm{~mm})$ für das jeweilige Material (N=Anzahl der Schienen; Var=Variable, $(\mathrm{N})=$ Mittelwert der Kräfte in Newton, $\mathrm{SD}=$ Standardabweichung in Newton).

\subsubsection{Horizontale Kräfte (Fx) der am Zahn 11 geschlitzten Schienen}

Die gemessenen horizontalen Kräfte (Fx) der am Zahn 11 geschlitzten Schienen (z11) bei einer Auslenkung von $\pm 0,151 \mathrm{~mm}$ werden in Tabelle 2 für die verschiedenen Materialien dargestellt. Die Mittelwerte bei vestibulärer Auslenkung liegen zwischen 2,47 N (SD 0,26 N) und 4,07 N (SD 0,74 N). Die Mittelwerte bei palatinaler Auslenkung betragen zwischen 1,94 N (SD 0,48 N) und 3,0 N (SD 0,40 N). Der niedrigste Wert wurde für beide Strecken für das Material Erkodur ${ }^{\circledR}$ gemessen, der höchste Wert ergab sich jeweils für Biolon ${ }^{\circledR}$. 


\begin{tabular}{|c|c|c|c|c|c|c|c|}
\hline Strecke & Materialstärke & Material & Schlitzung & $\mathrm{N}$ & Var. & Mittelwert (N) & $\mathrm{SD}(\mathrm{N})$ \\
\hline \multirow{3}{*}{$\begin{array}{l}-0,151 \mathrm{~mm} \text { pal. } \\
\text { Kippung }\end{array}$} & $1 \mathrm{~mm}$ & Biolon ${ }^{\circledR}$ & z11 & 5 & Fx & 3,0 & 0,40 \\
\hline & $1 \mathrm{~mm}$ & Erkodur $^{\circledR}$ & z11 & 5 & Fx & 1,94 & 0,48 \\
\hline & $1 \mathrm{~mm}$ & Ideal Clear $^{\circledR}$ & z11 & 5 & Fx & 2,28 & 0,20 \\
\hline \multirow{3}{*}{$\begin{array}{l}+0,151 \mathrm{~mm} \text { vest. } \\
\text { Kippung }\end{array}$} & $1 \mathrm{~mm}$ & Biolon $^{\circledR}$ & z11 & 5 & Fx & 4,07 & 0,26 \\
\hline & $1 \mathrm{~mm}$ & Erkodur $^{\circledR}$ & z11 & 5 & $\mathrm{Fx}$ & 2,47 & 0,74 \\
\hline & $1 \mathrm{~mm}$ & Ideal Clear $^{\circledR}$ & z11 & 5 & Fx & 2,78 & 0,55 \\
\hline
\end{tabular}

Tabelle 2: Mittelwerte und Standardabweichungen der horizontalen Kräfte (Fx). für die am Zahn 11 geschlitzten Schienen (z11) bei palatinaler und vestibulärer Auslenkung $( \pm 0,151 \mathrm{~mm})$ für das jeweilige Material (N=Anzahl der Schienen; Var=Variable, $(\mathrm{N})=$ Mittelwert der Kräfte in Newton, $\mathrm{SD}=$ Standardabweichung in Newton).

\subsubsection{Horizontale Kräfte (Fx) der an den Zähnen 12-21 geschlitzten Schienen}

Die Mittelwerte und Standardabweichungen der horizontal wirkenden Kräfte (Fx) der an den Zähnen 12-21 geschlitzten Schienen (z21-12) bei einer Auslenkung von $\pm 0,151 \mathrm{~mm}$ werden in Tabelle 3 nach den verwendeten Materialien differenziert dargestellt. Die Mittelwerte bei palatinaler Kippung liegen zwischen 1,48 N (SD 0,59 N) und 1,70 N (SD 0,12 N), die Mittelwerte bei vestibulärer Auslenkung zwischen 1,72 N (SD 0,89 N) und 2,09 N (SD 0,40 N). Der höchste Wert wurde für Biolon ${ }^{\circledR}$ gemessen, der niedrigste Wert für Ideal Clear ${ }^{\circledR}$. Insgesamt sind die Kräfte bei vestibulärer Kippung größer als bei palatinaler Kippung. 


\begin{tabular}{|c|c|c|c|c|c|c|c|}
\hline Strecke & Materialstärke & Material & Schlitzung & $\mathrm{N}$ & Var. & Mittelwert (N) & $\mathrm{SD}(\mathrm{N})$ \\
\hline \multirow{3}{*}{$\begin{array}{l}-0,151 \mathrm{~mm} \text { pal. } \\
\text { Kippung }\end{array}$} & $1 \mathrm{~mm}$ & Biolon $^{\circledR}$ & z12-21 & 5 & $\mathrm{Fx}$ & 1,70 & 0,12 \\
\hline & $1 \mathrm{~mm}$ & Erkodur $^{\circledR}$ & $\mathrm{z} 12-21$ & 5 & Fx & 1,49 & 0,25 \\
\hline & $1 \mathrm{~mm}$ & Ideal Clear $^{\circledR}$ & $\mathrm{z} 12-21$ & 5 & Fx & 1,48 & 0,59 \\
\hline \multirow{3}{*}{$\begin{array}{l}+0,151 \mathrm{~mm} \text { vest. } \\
\text { Kippung }\end{array}$} & $1 \mathrm{~mm}$ & Biolon ${ }^{\circledR}$ & $\mathrm{z} 12-21$ & 5 & $\mathrm{Fx}$ & 2,09 & 0,40 \\
\hline & $1 \mathrm{~mm}$ & Erkodur $^{\circledR}$ & $z 12-21$ & 5 & Fx & 1,75 & 0,33 \\
\hline & $1 \mathrm{~mm}$ & Ideal Clear ${ }^{\circledR}$ & z12-21 & 5 & Fx & 1,72 & 0,89 \\
\hline
\end{tabular}

Tabelle 3: Mittelwerte und Standardabweichungen der horizontalen Kräfte (Fx). für die an den Zähnen 12-21 geschlitzten Schienen (z12-21) bei palatinaler und vestibulärer Auslenkung $( \pm 0,151 \mathrm{~mm})$ für das jeweilige Material ( $\mathrm{N}=$ Anzahl der Schienen; Var=Variable, $(\mathrm{N})=$ Mittelwert der Kräfte in Newton, $\mathrm{SD}=$ Standardabweichung in Newton).

\subsection{Statistische Auswertung für die horizontalen Kräfte (Fx)}

Die Schlitzung hatte bei allen drei Materialien einen signifikanten Einfluss ( $<<0,0001)$ auf die abgegebene Kraft. Die Werte nahmen mit Zunahme der Schlitzgröße ab. Die Biolon ${ }^{\circledR}$ Schienen erzeugten im Vergleich zu den Schienen aus den anderen Materialien signifikant höhere Kräfte. Dieses Ergebnis war für die Bewegungsstrecke statistisch signifikant $(\mathrm{p}<0,0001)$.

Die Auswertung zeigt eine signifikante Wechselwirkung zwischen Material und Schlitzung (Tab. 4). D. h. die Schlitzung hat für die drei unterschiedlichen Materialen eine unterschiedliche Wirkung. In Abbildung 9 zeigt sich dieser Effekt darin, dass die auftretenden Kräfte für die verschiedenen Materialien der über drei Zähne geschlitzten Schienen (z12-21) sich kaum unterscheiden. Bei den Messungen der Schienen ohne Schlitz oder mit Schlitzung am Zahn 11 waren dagegen größere Unterschiede zwischen den einzelnen Materialien erkennbar. 


\begin{tabular}{|l|l|}
\hline Effekt & P-Wert \\
\hline Strecke & $<0,0001$ \\
\hline Material & $<0,0001$ \\
\hline Strecke vs. Material & 0,6479 \\
\hline Schlitzung & $<0,0001$ \\
\hline Strecke vs. Schlitzung & 0,4201 \\
\hline Material vs. Schlitzung & 0,0429 \\
\hline Strecke vs. Material vs. Schlitzung & 0,8381 \\
\hline
\end{tabular}

Tabelle 4: Tabellarische Darstellung der Ergebnisse der Varianzanalyse der horizontalen Kräfte (Fx) für die Materialien, Auslenkungsstrecken und Schlitzungen sowie deren Wechselwirkungen.

Schlitzung: ohne

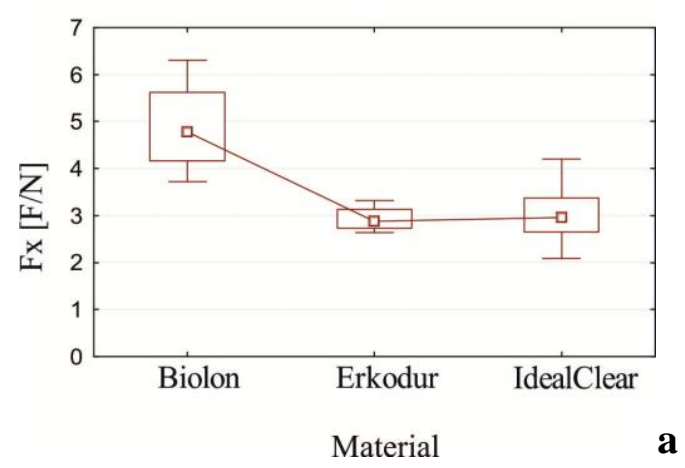

Schlitzung: z12-21

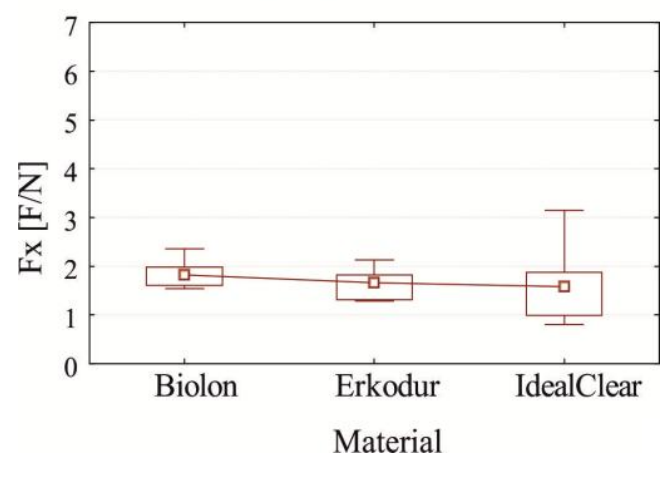

Schlitzung: z11

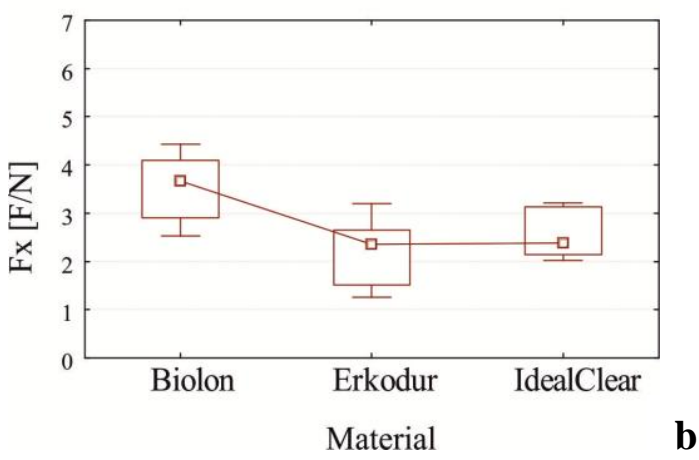

b

Abbildung 9: Darstellung der horizontalen Kräfte (Fx) für die gemessenen Materialien (Biolon ${ }^{\circledR}$, Erkodur $^{\circledR}$ und Ideal Clear ${ }^{\circledR}$ ) getrennt für die jeweilige Schlitzung (a-c). 
Abbildung 10 veranschaulicht dieses Ergebnis aus einem anderen Blickwinkel: Bei dem Material Biolon ${ }^{\circledR}$ ist der Einfluss der Schlitzung stärker als bei den beiden anderen Materialien; der Unterschied zwischen den Schlitzungen ist stärker als bei den beiden anderen Materialien. Die weitere Auswertung erfolgt daher getrennt für die verschiedenen Materialien $\left(\right.$ Biolon $^{\circledR}$, Erkodur $^{\circledR}$, Ideal Clear $\left.^{\circledR}\right)$.
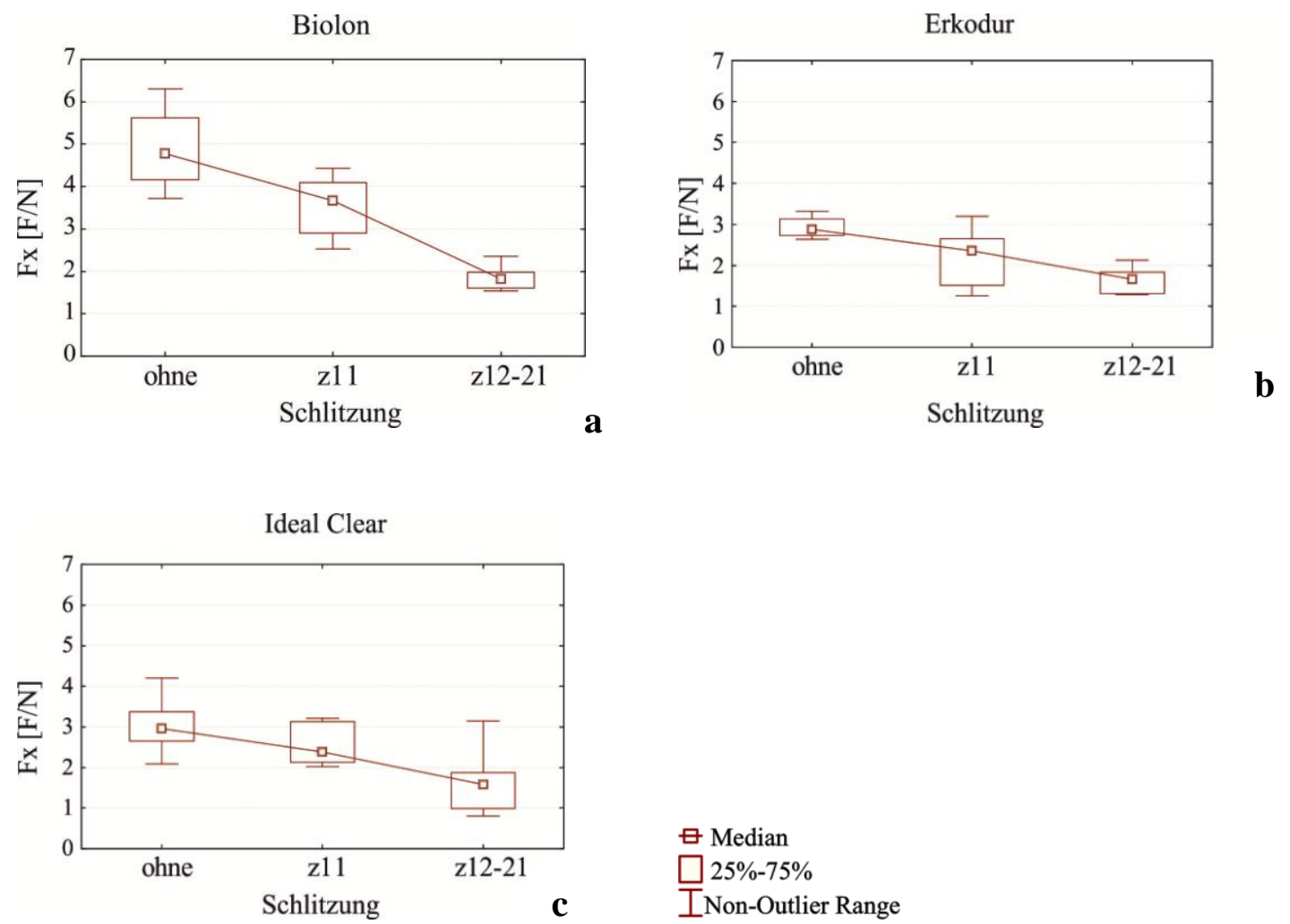

Abbildung 10: Gegenüberstellung der horizontalen Kräfte $(\mathrm{Fx})$ bei der jeweiligen Schlitzung getrennt für die einzelnen Materialien Biolon ${ }^{\circledR}(a)$ Erkodur $^{\circledR}$ (b) und Ideal Clear ${ }^{\circledR}$ (c). 


\subsubsection{Biolon ${ }^{\circledR}$}

Für das Material Biolon ${ }^{\circledR}$ lässt sich sowohl ein signifikanter Einfluss der Strecke $(p<0,0001)$ als auch des Faktors Schlitzung ( $p<0,0001)$ nachweisen (Tab. 5): Mit der Länge des Schlitzes nimmt die Kraft unabhängig von der Kipprichtung (Strecke: $\pm 0,151 \mathrm{~mm}$ ) ab. Es lässt sich des Weiteren zeigen, dass die Kräfte bei palatinaler Kipprichtung geringer ausfallen als bei vestibulärer Kipprichtung (Abb. 11).

\begin{tabular}{|l|l|}
\hline Effekt & P-Wert \\
\hline Strecke & $<0,0001$ \\
\hline Schlitzung & $<0,0001$ \\
\hline Strecke vs. Schlitzung & 0,1995 \\
\hline
\end{tabular}

Tabelle 5: Tabellarische Darstellung der Ergebnisse der Varianzanalyse für das Material Biolon ${ }^{\circledR}$.
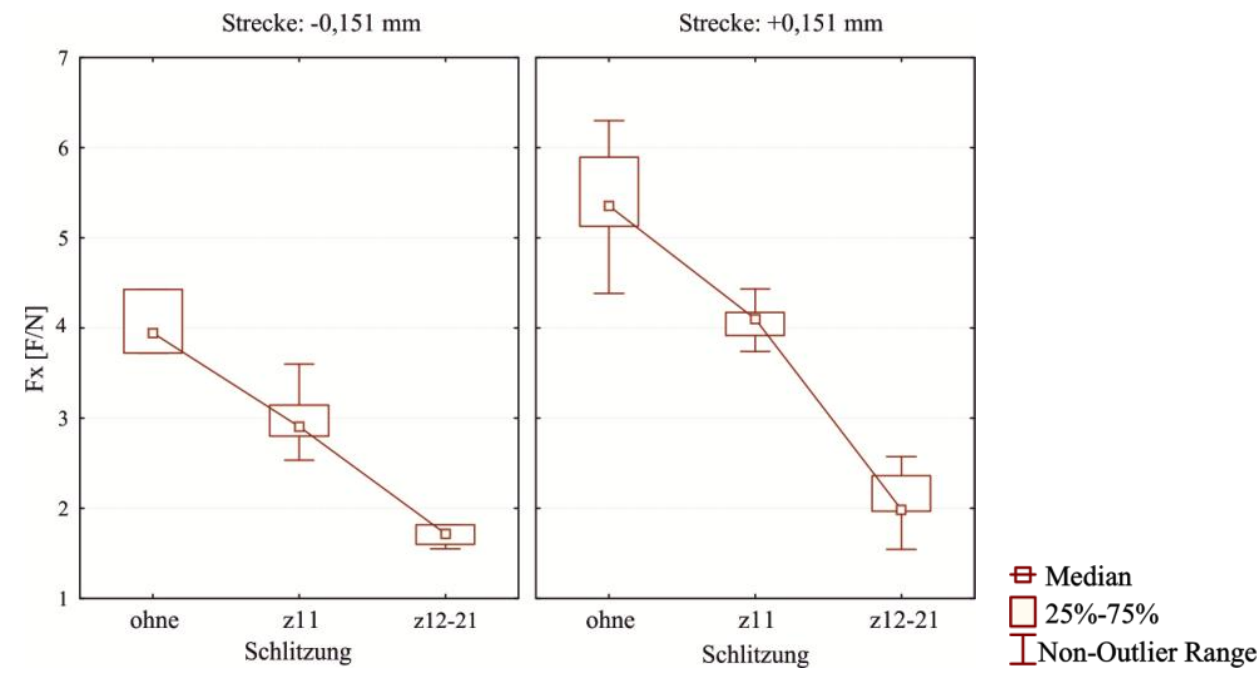

Abbildung 11: Graphische Darstellung der signifikanten Wechselwirkung der Schlitzungen für das Material Biolon ${ }^{\circledR}$ getrennt für die beiden Auslenkungsstrecken $( \pm 0,151 \mathrm{~mm})$. 


\subsubsection{Erkodur $^{\circledR}$}

Für das Material Erkodur ${ }^{\circledR}$ lässt sich sowohl ein signifikanter Einfluss der Strecke $(p<0,0107)$ als auch des Faktors Schlitzung ( $p<0,0001)$ nachweisen (Tab. 6): Mit der Länge des Schlitzes nimmt auch hier die Kraft unabhängig von der Kipprichtung (Strecke $\pm 0,151 \mathrm{~mm}$ ) ab. Es lässt sich ebenfalls zeigen, dass die Kräfte bei vestibulärer Auslenkung stärker sind als bei palatinaler Auslenkung (Abb. 12).

\begin{tabular}{|l|l|}
\hline Effekt & P-Wert \\
\hline Strecke & $<0,0107$ \\
\hline Schlitzung & $<0,0001$ \\
\hline Strecke vs. Schlitzung & 0,7348 \\
\hline
\end{tabular}

Tabelle 6: Tabellarische Darstellung der Ergebnisse der Varianzanalyse für das Material Erkodur ${ }^{\circledR}$.
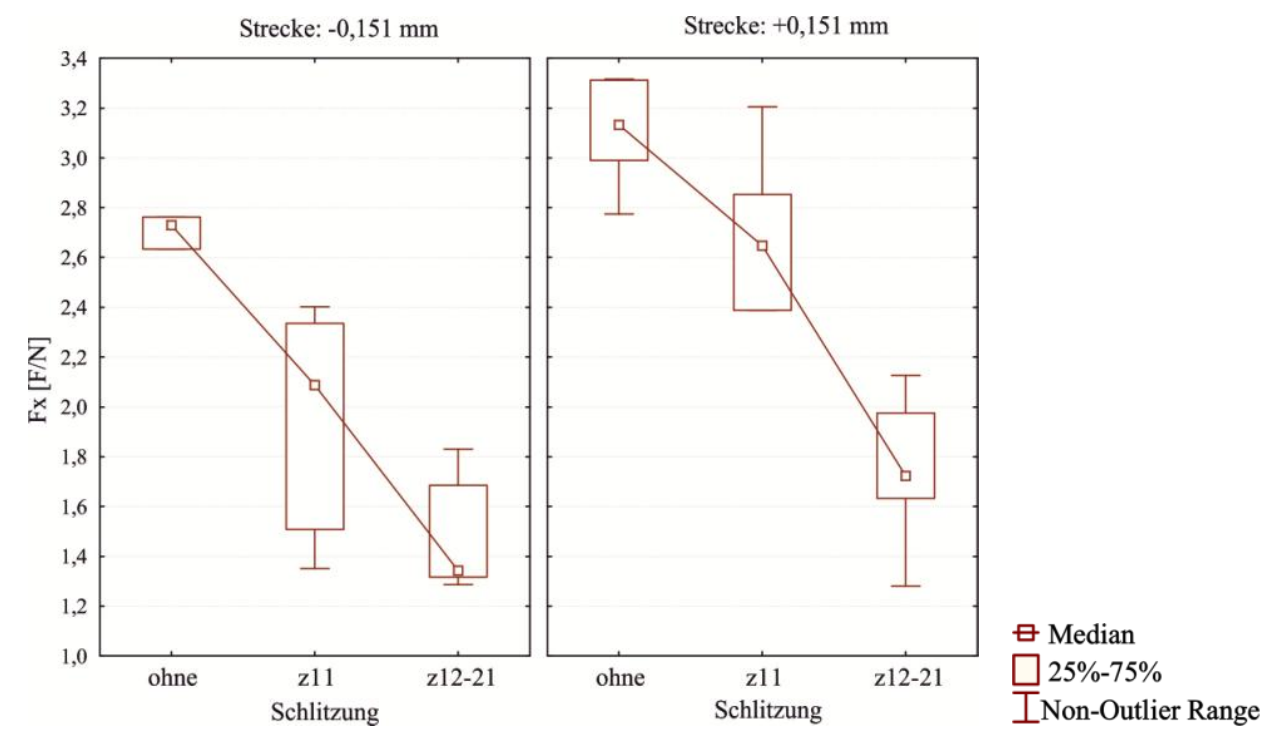

Abbildung 12: Graphische Darstellung der signifikanten Wechselwirkung der Schlitzungen für das Material Erkodur ${ }^{\circledR}$ getrennt für die beiden Auslenkungsstrecken $( \pm 0,151 \mathrm{~mm})$. 


\subsubsection{Ideal Clear ${ }^{\circledR}$}

Für das Material Ideal Clear ${ }^{\circledR}$ lässt sich kein signifikanter Einfluss der Strecke $(p<0,2087)$ feststellen (Tab. 7). Das bedeutet, dass hier die Schlitzung ( $p<0,0001)$ einen Einfluss auf die gemessene Kraft hat, die gemessene Kraft jedoch in beide Kipprichtungen ungefähr gleich stark ist. Die Kraft nimmt mit Länge des Schlitzes ab (Abb. 13).

\begin{tabular}{|l|l|}
\hline Effekt & P-Wert \\
\hline Strecke & $<0,2087$ \\
\hline Schlitzung & $<0,0001$ \\
\hline Strecke vs. Schlitzung & 0,6635 \\
\hline
\end{tabular}

Tabelle 7: Tabellarische Darstellung der Ergebnisse der Varianzanalyse für das Material Ideal Clear ${ }^{\circledR}$.
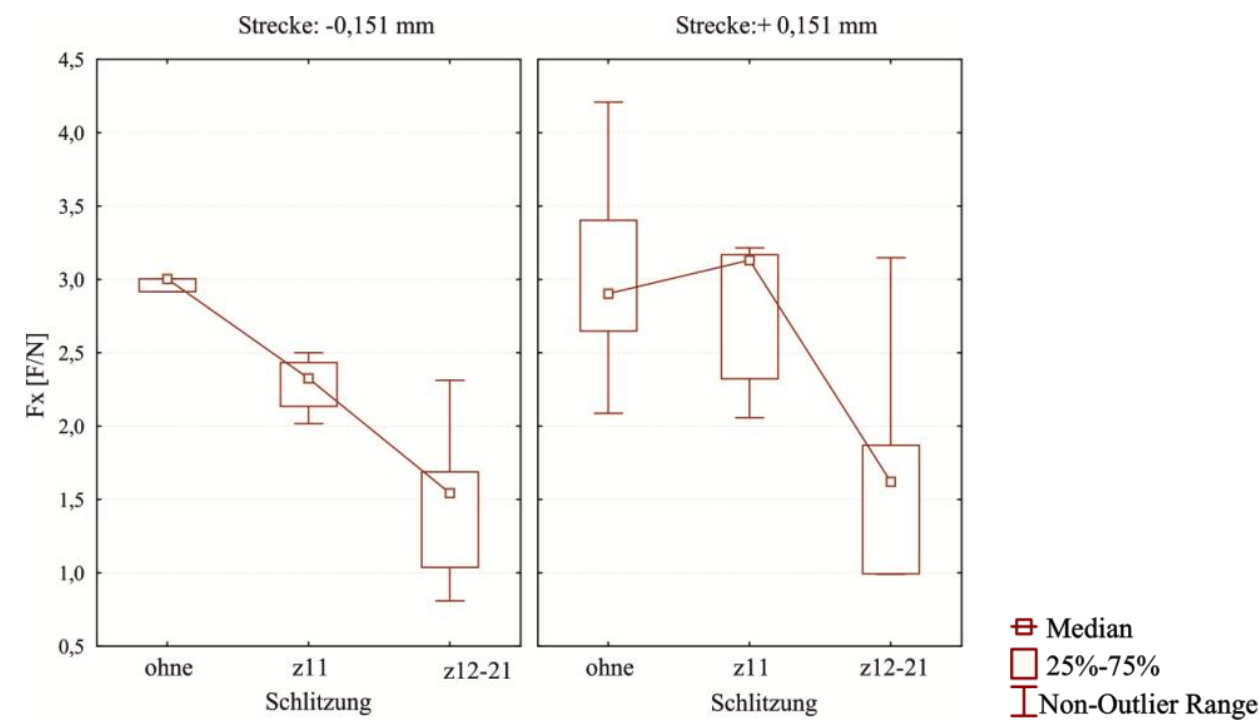

Abbildung 13: Graphische Darstellung der signifikanten Wechselwirkung der Schlitzungen für das Material Ideal Clear ${ }^{\circledR}$ getrennt für die beiden Auslenkungsstrecken $( \pm 0,151 \mathrm{~mm})$. 


\subsection{Vertikale Kräfte}

\subsubsection{Vertikale Kräfte $(\mathrm{Fz})$ ungeschlitzter Schienen}

Für die Ergebnisse der vertikalen Kräfte (Fz) gilt, dass die Vorzeichen Ausdruck der Wirkrichtung der Kraft sind. Negative Vorzeichen stehen für ein intrusives Fz und positive Messwerte für ein extrusives Fz.

Die Mittelwerte der vertikalen Kräfte bei palatinaler Auslenkung sind für die drei Materialien bei ungeschlitzten Schienen nahezu identisch. Sie liegen zwischen -0,02 N (SD 0,22 N) und 0,16 N (SD 0,13 N). Die Mittelwerte bei vestibulärer Auslenkung betragen zwischen -1,0 N $(\mathrm{SD} 0,29 \mathrm{~N})$ und $-2,55 \mathrm{~N}(\mathrm{SD} 0,46 \mathrm{~N})$. Insgesamt sind die Kräfte bei vestibulärer Kippung größer als bei palatinaler Kippung. Der höchste Wert wurde unabhängig von der Strecke für das Material Biolon ${ }^{\circledR}$ gemessen, der niedrigste ergab sich bei palatinaler Auslenkung und bei vestibulärer Auslenkung für Ideal Clear ${ }^{\circledR}$ (Tab. 8).

\begin{tabular}{|c|c|c|c|c|c|c|c|}
\hline Strecke & Materialstärke & Material & Schlitzung & $\mathrm{N}$ & Var. & Mittelwert (N) & $\mathrm{SD}(\mathrm{N})$ \\
\hline \multirow{3}{*}{$\begin{array}{l}-0,151 \mathrm{~mm} \text { pal. } \\
\text { Kippung }\end{array}$} & $1 \mathrm{~mm}$ & Biolon $^{\circledR}$ & Ohne & 5 & $\mathrm{Fz}$ & $-0,16$ & 0,13 \\
\hline & $1 \mathrm{~mm}$ & Erkodur $^{\circledR}$ & Ohne & 5 & $\mathrm{Fz}$ & 0,03 & 0,19 \\
\hline & $1 \mathrm{~mm}$ & Ideal Clear ${ }^{\circledR}$ & Ohne & 5 & $\mathrm{Fz}$ & $-0,02$ & 0,22 \\
\hline \multirow{3}{*}{$\begin{array}{l}+0,151 \mathrm{~mm} \text { vest. } \\
\text { Kippung }\end{array}$} & $1 \mathrm{~mm}$ & Biolon $^{\circledR}$ & Ohne & 5 & $\mathrm{Fz}$ & $-2,55$ & 0,46 \\
\hline & $1 \mathrm{~mm}$ & Erkodur $^{\circledR}$ & Ohne & 5 & $\mathrm{Fz}$ & $-1,13$ & 0,25 \\
\hline & $1 \mathrm{~mm}$ & Ideal Clear ${ }^{\circledR}$ & Ohne & 5 & $\mathrm{Fz}$ & $-1,00$ & 0,29 \\
\hline
\end{tabular}

Tabelle 8: Mittelwerte und Standardabweichungen der intrusiven Kräfte (Fz) für die ungeschlitzten Schienen bei palatinaler und vestibulärer Auslenkung $( \pm 0,151 \mathrm{~mm})$ für das jeweilige Material $(\mathrm{N}=$ Anzahl der Schienen; Var=Variable, $(\mathrm{N})=$ Mittelwert der Kräfte in Newton, $\mathrm{SD}=$ Standardabweichung in Newton). 


\subsubsection{Vertikale Kräfte (Fz) der am Zahn 11 geschlitzten Schienen}

Die Werte der vertikalen Kräfte (Fz) für die Strecke $+0,151 \mathrm{~mm}$ liegen bei den am Zahn 11 geschlitzten Schienen zwischen -0,58 N (SD 0,20 N) und -0,69 N (SD 0,31 N) und sind somit für alle drei Materialien in etwa gleich stark. Die Mittelwerte bei palatinaler Auslenkung bewegen sich zwischen 0,10 N (SD 0,35 N) und 0,19 N (SD 0,59 N). Der geringste Wert für die Strecke $-0,151 \mathrm{~mm}$ ergab sich für Erkodur ${ }^{\circledR}$. Für die Strecke $+0,151 \mathrm{~mm}$ wurde der geringste Wert für Ideal Clear ${ }^{\circledR}$ gemessen. Der größte Wert wurde unabhängig von der Strecke für Biolon ${ }^{\circledR}$ ermittelt (Tab. 9).

\begin{tabular}{|c|c|c|c|c|c|c|c|}
\hline Strecke & Materialstärke & Material & Schlitzung & $\mathrm{N}$ & Var. & Mittelwert (N) & $\mathrm{SD}(\mathrm{N})$ \\
\hline \multirow{3}{*}{$\begin{array}{l}-0,151 \mathrm{~mm} \text { pal. } \\
\text { Kippung }\end{array}$} & $1 \mathrm{~mm}$ & Biolon $^{\circledR}$ & $\mathrm{z} 11$ & 5 & $\mathrm{Fz}$ & 0,19 & 0,59 \\
\hline & $1 \mathrm{~mm}$ & Erkodur $^{\circledR}$ & z11 & 5 & $\mathrm{Fz}$ & 0,11 & 0,17 \\
\hline & $1 \mathrm{~mm}$ & Ideal Clear ${ }^{\circledR}$ & $\mathrm{z} 11$ & 5 & $\mathrm{Fz}$ & 0,10 & 0,35 \\
\hline \multirow{3}{*}{$\begin{array}{l}+0,151 \mathrm{~mm} \text { vest. } \\
\text { Kippung }\end{array}$} & $1 \mathrm{~mm}$ & Biolon $^{\circledR}$ & z11 & 5 & $\mathrm{Fz}$ & $-0,69$ & 0,31 \\
\hline & $1 \mathrm{~mm}$ & Erkodur $^{\circledR}$ & z11 & 5 & $\mathrm{Fz}$ & $-0,65$ & 0,17 \\
\hline & $1 \mathrm{~mm}$ & Ideal Clear ${ }^{\circledR}$ & $\mathrm{z} 11$ & 5 & $\mathrm{Fz}$ & $-0,58$ & 0,20 \\
\hline
\end{tabular}

Tabelle 9: Mittelwerte und Standardabweichungen der intrusiven Kräfte (Fz) für die am Zahn 11 geschlitzten Schienen (z11) bei palatinaler und vestibulärer Auslenkung $( \pm 0,151 \mathrm{~mm})$ für das jeweilige Material $(\mathrm{N}=$ Anzahl der Schienen; Var=Variable, $(\mathrm{N})=$ Mittelwert der Kräfte in Newton, $\mathrm{SD}=$ Standardabweichung in Newton). 


\subsubsection{Vertikale Kräfte (Fz) der an den Zähnen 12-21 geschlitzten Schienen}

Der höchste Wert der vertikalen Kräfte (Fz) für die Strecke -0,151 mm wurde bei an den Zähnen 12-21 geschlitzten Schienen für Biolon ${ }^{\circledR}(0,51 \mathrm{~N})$ ermittelt, der niedrigste Wert für Ideal Clear ${ }^{\circledR}(0,26 \mathrm{~N})$. Für die Strecke $+0,151 \mathrm{~mm}$ ergab sich hingegen der niedrigste Wert für Biolon $^{\circledR}(-0,35 \mathrm{~N})$ und der höchste Wert für Erkodur $^{\circledR}(-0,48 \mathrm{~N})$.

Die Mittelwerte der intrusiven Kräfte liegen demzufolge bei Kippung nach vestibulär zwischen $-0,35 \mathrm{~N}(\mathrm{SD} 0,18 \mathrm{~N})$ und $-0,48 \mathrm{~N}(\mathrm{SD} 0,19 \mathrm{~N})$, die Mittelwerte bei palatinaler Auslenkung zwischen 0,26 N (SD 0,33 N) und 0,51 N (SD 0,16 N) (Tab. 10).

\begin{tabular}{|c|c|c|c|c|c|c|c|}
\hline Strecke & Materialstärke & Material & Schlitzung & $\mathrm{N}$ & Var. & Mittelwert (N) & $\mathrm{SD}(\mathrm{N})$ \\
\hline \multirow{3}{*}{$\begin{array}{l}-0,151 \mathrm{~mm} \text { pal. } \\
\text { Kippung }\end{array}$} & $1 \mathrm{~mm}$ & Biolon $^{\circledR}$ & $\mathrm{z} 12-21$ & 5 & $\mathrm{Fz}$ & 0,51 & 0,16 \\
\hline & $1 \mathrm{~mm}$ & Erkodur $^{\circledR}$ & z12-21 & 5 & $\mathrm{Fz}$ & 0,32 & 0,25 \\
\hline & $1 \mathrm{~mm}$ & Ideal Clear ${ }^{\circledR}$ & z12-21 & 5 & $\mathrm{Fz}$ & 0,26 & 0,33 \\
\hline \multirow{3}{*}{$\begin{array}{l}+0,151 \mathrm{~mm} \text { vest. } \\
\text { Kippung }\end{array}$} & $1 \mathrm{~mm}$ & Biolon $^{\circledR}$ & $\mathrm{z} 12-21$ & 5 & $\mathrm{Fz}$ & $-0,35$ & 0,18 \\
\hline & $1 \mathrm{~mm}$ & Erkodur $^{\circledR}$ & z12-21 & 5 & $\mathrm{Fz}$ & $-0,48$ & 0,19 \\
\hline & $1 \mathrm{~mm}$ & Ideal Clear $^{\circledR}$ & $\mathrm{z} 12-21$ & 5 & $\mathrm{Fz}$ & $-0,37$ & 0,33 \\
\hline
\end{tabular}

Tabelle 10: Mittelwerte und Standardabweichungen der intrusiven Kräfte (Fz) für die an den Zähnen 12-21 geschlitzten Schienen (z12-21) bei palatinaler und vestibulärer Auslenkung $( \pm 0,151 \mathrm{~mm})$ für das jeweilige Material $(\mathrm{N}=$ Anzahl der Schienen; Var=Variable, $(\mathrm{N})=$ Mittelwert der Kräfte in Newton, $\mathrm{SD}=$ Standardabweichung in Newton). 


\subsection{Statistische Auswertung für die vertikalen Kräfte $(\mathrm{Fz})$}

Die statistische Auswertung zeigt einen signifikanten Einfluss $(<0,0001)$ der Auslenkungsrichtung $( \pm 0,151 \mathrm{~mm})$ und der Schlitzung auf die vertikalen Kräfte $(\mathrm{Fz})$ $(<0,0001)$. Dieser Effekt war jedoch nicht statistisch signifikant für die jeweiligen Materialien. Es besteht keine signifikante Wechselwirkung zwischen Strecke und Material, Material und Schlitzung oder Strecke und Schlitzung.

\begin{tabular}{|l|l|}
\hline Effekt & P-Wert \\
\hline Strecke & $<0,0001$ \\
\hline Material & 0,4672 \\
\hline Strecke vs. Material & 0,8743 \\
\hline Schlitzung & $<0,0001$ \\
\hline Strecke vs. Schlitzung & 0,3741 \\
\hline Material vs. Schlitzung & 0,1590 \\
\hline Strecke vs. Material vs. Schlitzung & 0,6148 \\
\hline
\end{tabular}

Tabelle 11: Tabellarische Darstellung der Ergebnisse der Varianzanalyse der intrusiven Kräfte (Fz) für die Materialien, Auslenkungsstrecken und Schlitzungen sowie deren Wechselwirkungen.

Die Mittelwerte für Fz waren für die Kippung nach vestibulär (+0,151 mm) stets negativ, was für eine intrusive Kraft steht. Bei der Auslenkung nach palatinal $(-0,151 \mathrm{~mm})$ sind, bis auf zwei Ausnahmen (z0: Biolon; z0: Ideal Clear), nur positive Mittelwerte ermittelt worden, was für extrusive Kräfte steht (Abb. 15, Abb. 16).

Abbildung 14 zeigt die gemessenen Kräfte für die einzelnen Materialien bei der jeweiligen Schlitzung, getrennt für die beiden Auslenkungsstrecken. Erkennbar ist die Abnahme der Kraft mit Zunahme der Schlitzgröße sowie der Kraftrichtungswechsel bei der Kippung nach palatinal $(-0,151 \mathrm{~mm})$. 


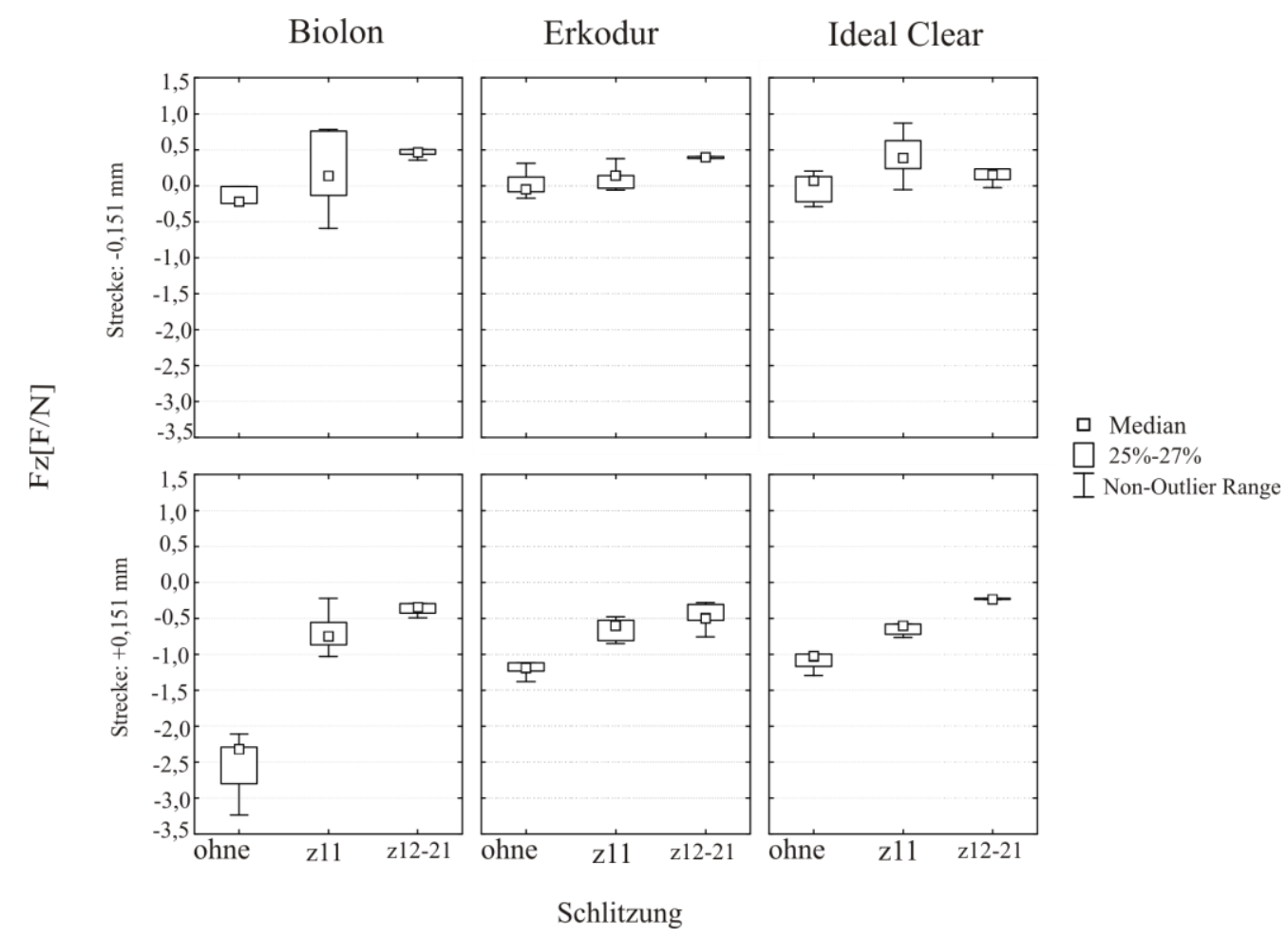

Abbildung 14: Graphische Darstellung der vertikalen Kräfte $(\mathrm{Fz})$ bei der jeweiligen Auslenkungsstrecke $( \pm 0,151 \mathrm{~mm})$ getrennt für die drei Materialien Biolon ${ }^{\circledR}$, Erkodur $^{\circledR}$, Ideal Clear ${ }^{\circledR}$ ) in Abhängigkeit der jeweilige Schlitzung (ohne, z11, z12-21).
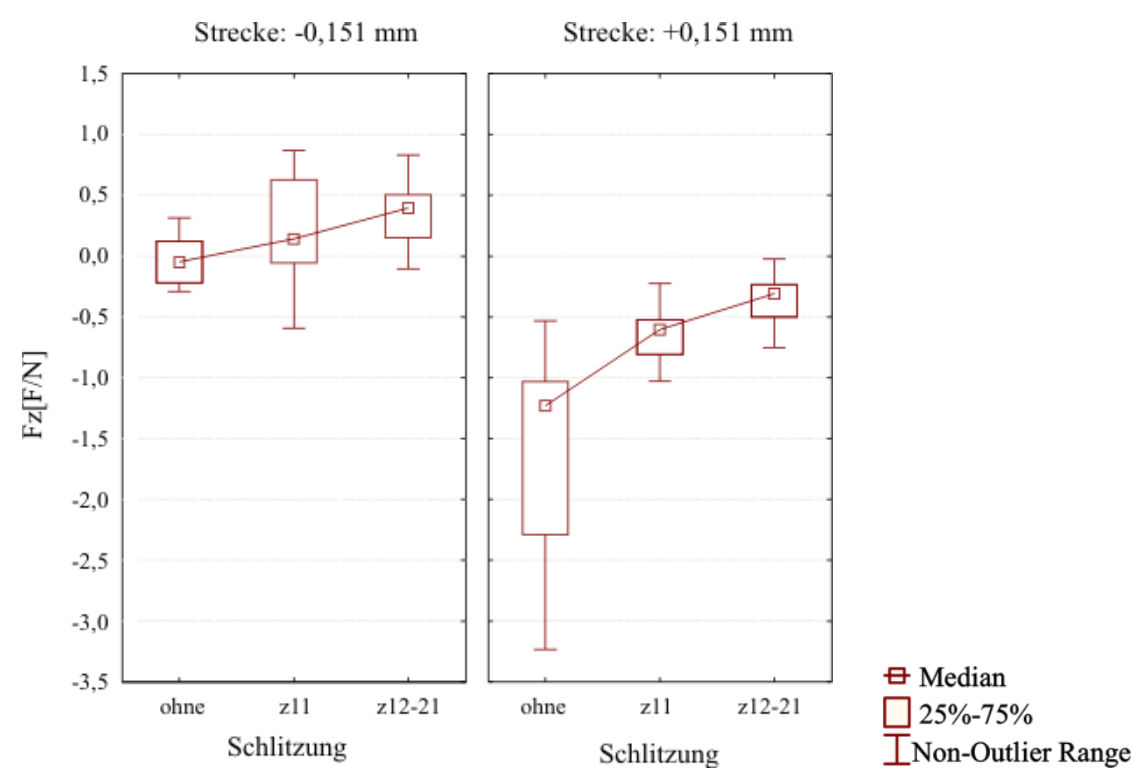

Abbildung 15: Graphische Darstellung der Wechselwirkung zwischen Strecke und Schlitzung getrennt für die palatinale Kippung (Strecke $-0,151 \mathrm{~mm}$ ) und die vestibuläre Kippung (Strecke $+0,151 \mathrm{~mm}$ ). Es wurden die Messwerte aller Schienen unabhängig vom Material in die Auswertung einbezogen. 

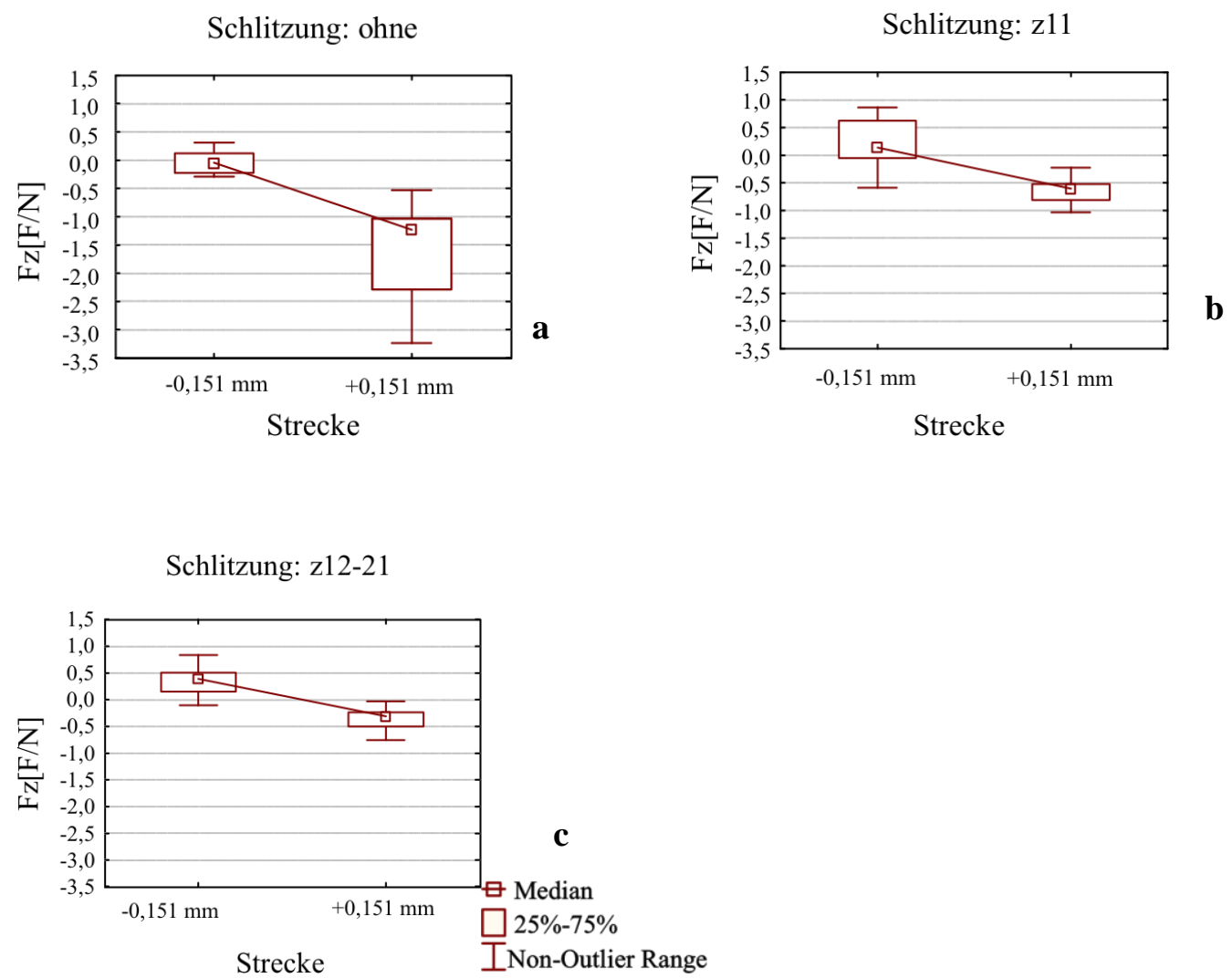

Abbildung 16: Gegenüberstellung der vertikalen Kräfte (Fz) bei der jeweiligen Auslenkungsstrecke $( \pm 0,151 \mathrm{~mm})$ getrennt für die ungeschlitzten (a), die am Zahn 11 (b) und an den Zähnen 12-21 geschlitzten Schienen (c). Es wurden die Messwerte aller Schienen unabhängig vom Material in die Auswertung einbezogen. 


\section{Diskussion}

In der vorliegenden Studie wurden die initial auftretenden Kräfte bei Kippbewegung eines ersten Oberkieferfrontzahnes mittels modifizierter Tiefziehschienen in vitro untersucht.

Die Kippung erfolgte in palatinaler und vestibulärer Richtung von $0^{\prime}$ bis $\pm 22,2^{\prime}$ (Bogenminuten) in 2,7' Schritten. Von Interesse waren die gemessenen vertikalen (Fz) und horizontalen Kräfte $(\mathrm{Fx})$ bei $\pm 22,2^{\prime}$ (Bogenminuten), die einer Auslenkungstrecke der Inzisalkante des Messzahnes von $\pm 0,151 \mathrm{~mm}$ entsprechen.

In der Vergangenheit beschrieben einige Autoren bereits die Behandlungen verschiedener Zahnfehlstellungen mit thermoplastisch geformten Schienen (VLASKALIC und BOYD 2002, Wong 2002, Bollen et al. 2003, Clements et al. 2003, DJeu et al. 2005). Mit der Kraftabgabe solcher Schienen befassten sich jedoch bisher nur wenige Studien (WARUNEK et al. 1989, Rost et al. 1995, BARBAGALLO et al. 2008b, KwON et al. 2008). Eine systematische Untersuchung der biomechanischen Zusammenhänge wurde erst durch eine aktuelle Studienreihe, zu der auch die vorliegende Untersuchung zählt, durchgeführt (ENGELKE 2010, HAHN 2009, HAHN et al. 2009a, HAHN et al. 2009b, HAHN et al. 2010a, HAHN et al. 2010b, HAHN et al. 2011).

Die Kraftabgabe von durch Schlitzung modifizierten Schienen wurde in der Literatur noch nicht beschrieben. Primär wurde der Frage nachgegangen, ob und inwieweit die Ausdehnung des Schlitzes einen Einfluss auf die Kraft hat und welche Bedeutung dabei die einzelnen Materialien und die Richtung der Auslenkung haben.

Im anschließenden Abschnitt der vorliegenden Studie sollen sowohl der Versuchsaufbau als auch die Untersuchungsergebnisse kritisch diskutiert werden.

\subsection{Diskussion von Material und Methode}

\subsubsection{Einfluss der Messmethode}

ROSARIUS et al. (1996) publizierten das erste Konzept einer Messvorrichtung, die Kraftsysteme in vivo erfasste. Mit Hilfe von teilbaren Spezialbrackets konnten vom Bogen ausgehende Kräfte direkt im Mund des Patienten durch einen 3-D-Sensor gemessen werden. In der Literatur lassen sich aufgrund der Schwierigkeit der Drehmoment-Kraft-Messung von 
Multibandapparaturen nur wenige weitere Studien finden (LAPATKI und PAUL 2007, LAPATKI et al. 2007).

Zur Erfassung der Kraftabgabe von Schienen wurden druckempfindliche Folien mit Farbindikator (Pressurex ${ }^{\circledR}$ Fuji Photo Film Co., Ltd, Tokyo, Japan) eingesetzt. Entsprechend dem applizierten Druck veränderten die Folien ihre Farbe, was auf die verwendete Kraft schließen ließ (BARBAGALlo et al. 2008b). Dabei konnte jedoch keine Trennung zwischen horizontalen und vertikalen Kräften erfolgen.

Bei der für diese Studie verwendete modularen in-vitro-Messapparatur wurde aufgrund der komplexen Eigenschaften des Parodontiums bei Belastung, die nicht mit einer Messapparatur zu simulieren sind (NATAli et al. 2004, CATTANEO et al. 2008), eine starre Verbindung zwischen Sensor und Messzahn gewählt. Dies ist eine weit verbreitete Methode in der orthodontischen Kraftmessung (BARTZELA et al. 2007, WALKER et al. 2007, WANG et al. 2007, BACCETTI et al. 2008, LiM et al. 2008, PANDis et al. 2008 a, PANDIS et al. 2008 b). Hierdurch sind jedoch nur initiale Kräfte messbar. Das bedeutet, dass die Kräfte mit der Apparatur erfasst werden, die unmittelbar nach dem Aufsetzen der Schiene auf den Messzahn entstehen, wenn infolge des viskoelastischen Charakters des Parodontalligaments noch keine Zahnbewegung erfolgt ist (NAKAMURA et al. 2008).

Ein Kraftabfall, wie er aufgrund der durch die initial erzeugte Schienenkraft bedingte Zahnbewegung entsteht, kann auf diese Weise nicht gemessen werden. Diese Überlegungen schränken die Aussagekraft der gemessenen Ergebnisse in Bezug auf die Kraftentwicklung über einen längeren Tragezeitraum der Schienen ein. Aussagen über Kraftwirkungsrichtungen und die initialen Kraftgrößen sowie die Kraftansatzpunkte und die daraus ableitbaren Bewegungsformen sind hingegen aufgrund der gemessenen Daten möglich.

\subsubsection{Einfluss des Materials}

Bei der Betrachtung der Ergebnisse wurde deutlich, dass die gemessenen Kräfte in Abhängigkeit vom Material variierten. Bei den gemessenen horizontalen Kräften (Fx) wurden mit den Schienen aus Biolon ${ }^{\circledR}(1,70 \mathrm{~N}-5,41 \mathrm{~N})$ signifikant höhere Kräfte erzeugt als mit den beiden anderen Materialien. Die Erkodur ${ }^{\circledR}$-Schienen $(1,49 \mathrm{~N}-3,11 \mathrm{~N})$ und die Ideal Clear ${ }^{\circledR}$ Schienen $(1,48 \mathrm{~N}-3,05 \mathrm{~N})$ wiesen für Fx im Schnitt ähnlich hohe Kräfte auf. Bei den intrusiven Kräften $(\mathrm{Fz})$ wiesen die Biolon ${ }^{\circledR}$-Schienen $(-0,32 \mathrm{~N}--2,5 \mathrm{~N})$ im Vergleich zu den anderen beiden Materialien (Erkodur ${ }^{\circledR}: 0,02 \mathrm{~N}--0,65 \mathrm{~N}$; Ideal Clear ${ }^{\circledR}:-0,02 \mathrm{~N}--0,58 \mathrm{~N}$ ) 
ebenfalls tendenziell die höchsten Kräfte auf. Dies war zwar nicht statistisch signifikant, ist jedoch in der grafischen Darstellung erkennbar (Abb. 14).

HAHN (2009) ermittelte in seinen Studien vergleichbare Ergebnisse. Unabhängig von der Bewegungsform (Kippung, Torque und Rotation) und der Auslenkungsstrecke zeigten sich die höchsten Kräfte fast ausnahmslos für die Biolon ${ }^{\circledR}$-Schienen (HAHN et al. 2009a, HAHN et al. 2009b, HAHN et al. 2010a, HAHN et al 2010b).

Zum einen könnten sich die Ergebnisse durch die unterschiedlichen Materialeigenschaften erklären lassen: Die Elastizität eines Materials hat einen Einfluss auf die entstehenden Kräfte (ROST et al. 1993); die verwendeten Materialien weisen individuelle Elastizitätsmodule auf. Die Erkodur ${ }^{\circledR}$ und Ideal Clear ${ }^{\circledR}$-Folien bestehen aus glycolmodifiziertem Polyethylenterephthalat und die Biolon ${ }^{\circledR}$-Folien sind aus Polyethylenterephthalat. Jedoch sind die Materialeigenschaften nicht so verschieden, dass sie allein für die oben genannten Ergebnisse herangezogen werden können.

Demzufolge könnte zum anderen das unterschiedliche Herstellungsverfahren der Schienen ursächlich sein, da zwei verschiedene Techniken zur Anwendung kamen: Die Schienen aus Biolon ${ }^{\circledR}$ wurden durch ein thermoplastisches Verfahren mittels Druck (6 Bar) hergestellt; die Tiefziehgeräte für die Erkodur ${ }^{\circledR}$ - und Ideal Clear $^{\circledR}$-Folien arbeiten mit Vakuum (0,8 Bar). Durch die Formgebung mittels Überdruck ist davon auszugehen, dass die Schienen aus Biolon ${ }^{\circledR}$ eine genauere Passung haben und somit eine höhere Friktion auf der Zahnreihe, wodurch die Gesamtverformung der Schienen aus Biolon ${ }^{\circledR}$ bei Kippbewegung stärker war als die der beiden anderen Materialien und somit die resultierende Rückstellkraft auf den Frontzahn größer war (siehe dazu Kapitel 4.2.1 Kraftentstehung an Schienen).

Bei der Herstellung der Erkodur ${ }^{\circledR}$-Schienen wurde zusätzlich mit einer Platzhalterfolie $(0,05$ $\mathrm{mm})$ gearbeitet, die nach dem Tiefziehen entfernt wurde. Dadurch war die Friktion der Schienen auf der Zahnreihe minimiert. Es erfolgte eine schwächere Gesamtverformung, wodurch sich die geringeren Rückstellkräfte der Erkodur ${ }^{\circledR}$-Schienen gegenüber den anderen Materialien erklären lassen. Ob die Platzhalterfolie jedoch einen wesentlichen Einfluss auf die lokale Deformation am zu therapierenden Zahn hat, bleibt aufgrund ihrer geringen Stärke fraglich. Diese beträgt vor dem Tiefziehvorgang nur $0,05 \mathrm{~mm}$ und wird durch den Tiefziehvorgang noch einmal wesentlich ausgedünnt. 


\subsection{Diskussion der Ergebnisse}

\subsubsection{Kraftentstehung an orthodontischen Schienen}

Bei der Kraftentstehung an thermoplastisch geformten Schienen wirken zwei Mechanismen zusammen: Zum einen werden die Kräfte durch eine inzisal wirkende Rückstellkraft der Schiene erzeugt, die beim Aufsetzen des Schienenkörpers durch den Widerstand entsteht, den der zu therapierende Zahn der Schiene an ihrem gemeinsamen Kontaktpunkt entgegenbringt. Es liegt eine lokale Verformung der Schiene im Bereich des zu therapierenden Zahnes vor. Zum anderen kommt es durch die Differenz zwischen Ist-Position des Zahnes und SollPosition, die in die Schiene eingearbeitet ist, bei Kippung zu einer Abhebung der Schiene im Frontzahnbereich. Die Schiene wird im Seitenzahnbereich durch Friktion auf den Zähnen fixiert, woraus eine Gesamtverformung des Schienenkörpers resultiert. Dadurch wirkt wiederum eine verstärkte vertikale Rückstellkraft auf den zu therapierenden Zahn (HAHN 2009) (Abb. 17).

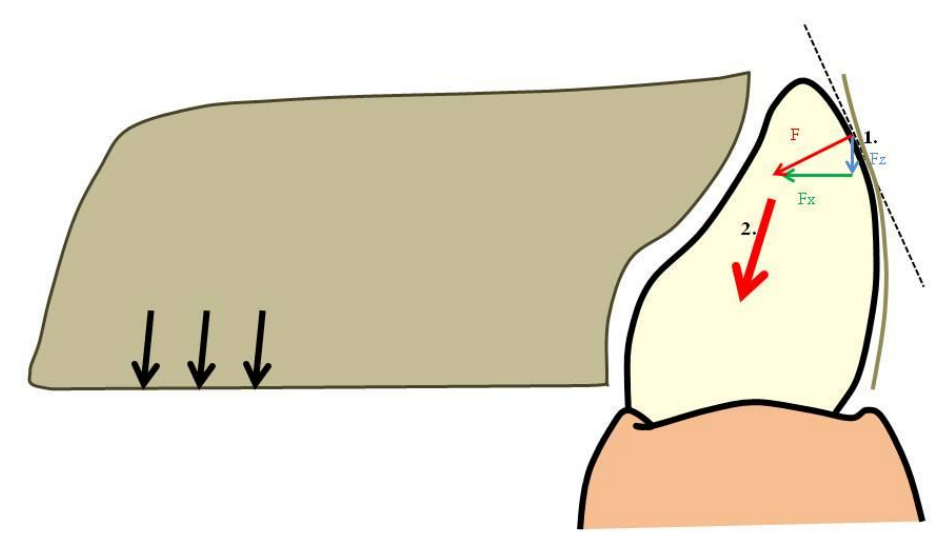

Abbildung 17: Darstellung der Kraftentstehung an modifizierten thermoplastischen Schienen. Durch Passungsungenauigkeiten zwischen der Schiene und dem Zahn kommt es dort zu einem Abheben der Schiene. Durch Friktion im Seitenzahnbereich (schwarze Pfeile) wird die Schiene dort auf der Zahnreihe gehalten. Durch diese beiden entgegengesetzt wirkenden Kräfte kommt es zu einer Verformung des gesamten Schienenkörpers mit einer verstärkten intrusiv wirkenden Kraftkomponente (2.). Die anderen Anteile der Kraftentstehung sind in der lokalen Verformung des Schienenkörpers im Kontaktbereich zwischen Schiene und Zahn zu suchen (1.) (modifiziert nach HAHN 2009). 


\subsubsection{Betrachtung der Kraftabnahme mit Zunahme der Schlitzgröße}

Die in dieser Studie verwendeten Schienen waren durch eine unterschiedlich stark ausgedehnte inzisale Schlitzung modifiziert. Dies hatte einen Einfluss auf die Kräfteentstehung an den Schienen: Die Ergebnisse der horizontalen und der vertikalen Kräfte zeigten, dass mit Zunahme der Schlitzgröße die Kräfte abnahmen.

Durch die Morphologie der Zähne zeichnen sich thermoplastisch geformte Schienen durch eine komplexe geometrische Form aus. Durch den Herstellungsprozess der Schiene lässt sich eine Versteifung des Materials finden, die von der marginalen Gingiva hin zur Inzisalkante, dem Bereich mit der stärksten Krümmung, zunimmt. Die Steigerung der Steifigkeit ist vergleichbar mit der Zunahme der Steifigkeit von einem Blatt Papier hin zur Wellpappe (ENGELKE 2010).

Das Phänomen der Kraftabnahme mit Zunahme der Schlitzung lässt sich dadurch erklären, dass sich durch die Schlitzung der Schiene das Spannungs-Dehnungs-Verhältnis veränderte. Mit Zunahme der Schlitzgröße ließ sich die Schiene in der Nähe des Kontaktbereiches zwischen Zahn und Schiene (knapp unterhalb der Inzisalkante) leichter aufdehnen. Durch die Schienenschlitzung war der Wellpappeneffekt reduziert und die betroffenen Areale der Schiene, die durch das Auslenken des Zahnes verformt wurden, brachten dem Zahn weniger Widerstand entgegen. Folglich wurde Material gleicher Dicke über einen längeren Bereich bis zur nächsten Materialversteifung ausgelenkt, weshalb als Konsequenz eine Kraftreduktion resultierte.

Das oben beschriebene Abheben der Schiene in Relation zur Bewegung reduzierte sich ebenso bis hin zum vollständigen Ausbleiben. Folglich kam es zu einer kleineren bzw. zu gar keiner Gesamtverformung des Schienenkörpers, wodurch die Rückstellkräfte bei den Schienen mit größerer Schlitzung geringer waren als bei den ungeschlitzten Schienen. Anhand der Abbildung 18 wird die Abnahme der Kraft mit Zunahme der Schlitzung noch einmal grafisch verdeutlicht.

Der Kontaktpunkt zwischen Schienenoberfläche und Zahn, an dem die Kraft bei einer ungeschlitzten Schiene erzeugt wird, liegt im Bereich der Schneidekante (HAHN 2009). Der Berührungspunkt ist von der Größe der Schlitzung und der Weite der Auslenkung abhängig. Durch die Schlitzung verschiebt sich der Kontaktpunkt zwischen Schiene und Zahnoberfläche, an dem die Kraft entsteht, Richtung marginal. Die entstehende Kraft ist senkrecht zur Zahnoberflächentangente. Die Neigung der Tangente wird mit Zunahme der Schlitzgröße steiler, weil der Kontaktpunkt zwischen Zahn und Schiene zunehmend nach 
marginal wandert. Bei der Zerlegung der Gesamtkraft (F) in die Teilkräfte (Fx und Fz) wird deutlich, dass sich diese Vektorkombination mit Zunahme der Schlitzung ändert (Abb. 18).

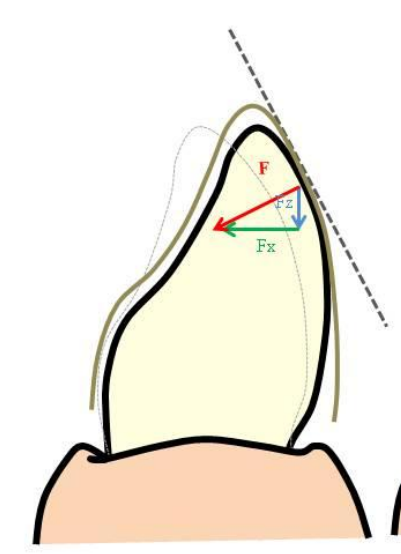

a

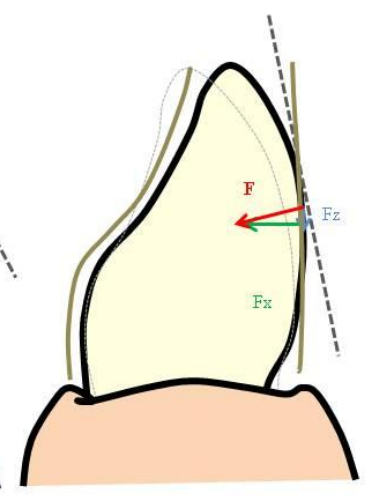

b

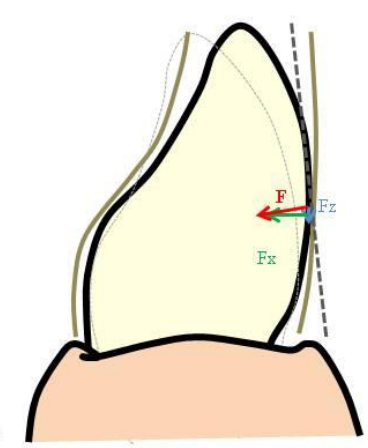

c

Abbildung 18: Darstellung der Neigung der Tangente am Kontaktpunkt zwischen Schieneninnenfläche und Zahnoberfläche bei der Kippung nach vestibulär. Mit Zunahme der Schlitzgröße (von a-c) ändert sich die Lage der Tangente. Je nach Gesamtkraft (F; roter Pfeil) resultiert eine andere Zerlegung der horizontalen (Fx; grüner Pfeil) und vertikalen (Fz; blauer Pfeil) Kraftvektoren. Die Gesamtkraft verändert sich mit dem Grad der Schlitzung: Je größer die Schlitzung, desto geringer die Kraft.

\subsubsection{Betrachtung des Kraftrichtungswechsels von intrusiven zu extrusiven Kräften}

Das Auftreten der intrusiven Kräfte konnte mit der Studienserie von HAHN (2009), zu der auch diese Untersuchung gehört, erstmals als universelles Phänomen für die Zahnbewegung mit thermoplastisch geformten Schienen systematisch analysiert werden.

Bei den für die vorliegende Studie durchgeführten Messungen wurde bei der Kippung nach palatinal erstmals eine Umkehrung der Kraftrichtung beobachtet. Die Werte wechselten von schwach intrusiven Kräften $(\mathrm{Fz})$ bei Schienen ohne Schlitzung bis hin zu extrusiven Kräften (Fz) mit zunehmender Schlitzgröße (Abb. 19). Der Kraftrichtungswechsel ist gekennzeichnet 
durch das wechselnde Vorzeichen von negativ zu positiv. Als Erklärung könnte die unterschiedliche Anatomie der Oral- und Labialfläche des Frontzahnes herangezogen werden: An Vestibulär- und Palatinalfläche lässt sich eine unterschiedliche Morphologie vorfinden. Die vestibuläre Zahnoberfläche ist konvex, während die Palatinalfläche sowohl konvexe als auch konkave Bereiche aufweist. Dadurch besteht bei der Krafterzeugung ein individuelles Wechselspiel zwischen Neigung und Form der inneren Schienenoberfläche und der Anatomie des Zahnes im Kontaktbereich zwischen Zahn und Schiene. Am Übergang zwischen konvexem und konkavem Bereich auf der palatinalen Seite des Zahnes findet sich eine Einbuchtung. Dieser Punkt ist entscheidend für den Kraftrichtungswechsel.

Dieser Zusammenhang wird durch die Abbildung 19 verdeutlicht. Bei den ungeschlitzten Schienen (Abb. 19a) liegt der Kontaktpunkt, an dem die Kraft erzeugt wird, sehr nah an der Inzisalkante, im konvexen Bereich. Mit Zunahme der Schlitzung würde der Kontaktpunkt weiter nach marginal wandern. Am Übergang zwischen konvexer und konkaver Oberfläche stünde die Tangente senkrecht und die Gesamtkraft F entspräche der Teilkraft Fx. Die vertikalen Kräfte (Fz) wären demzufolge gleich null (Abb. 19b). Bei den Schienen mit der größten Schlitzung würde der Kontaktpunkt noch weiter nach gingival wandern und läge schließlich im konkaven Bereich der Palatinalfläche, wodurch sich die Neigung der Tangente wiederum verändern würde. Folglich würde eine Gesamtkraft (F) mit einer anderen Wirkungsrichtung resultieren, wodurch auch die Vektorkombination aus Fx und Fz verändert wäre und sich speziell die Richtung von Fz umkehren würde. 


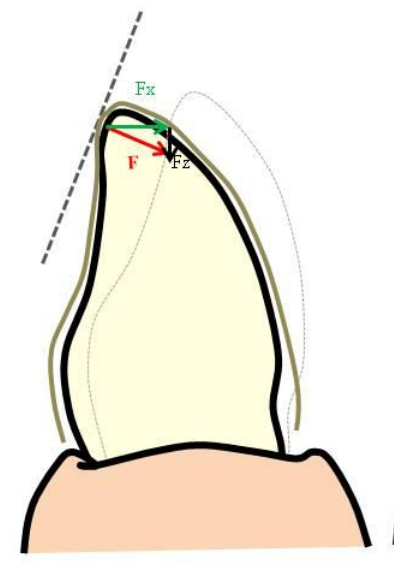

a

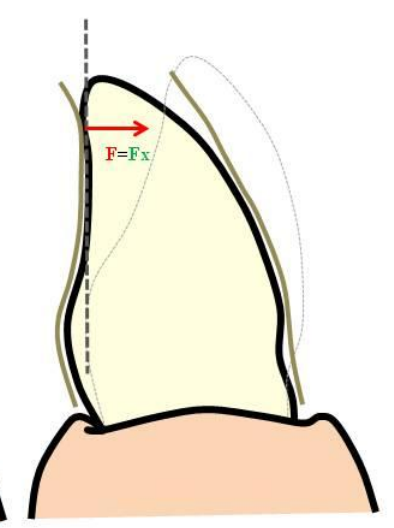

b

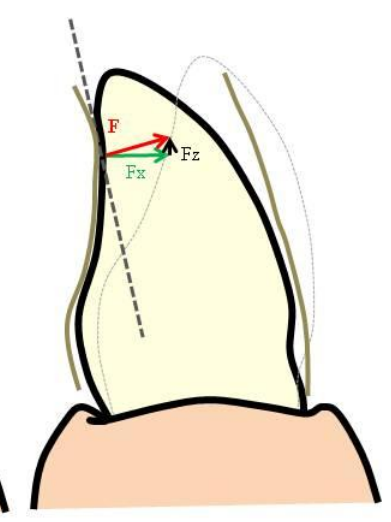

c

Abbildung 19: Darstellung des Wechsels von intrusiven (a) zu extrusiven (c) Kräften mit Zunahme der Schlitzung bei der Kippung nach palatinal. Die Neigung der Tangente verändert sich, da der Kontaktpunkt zwischen Schiene und Zahn nach unten wandert, entlang der konvex-konkaven Palatinalfläche. Das Zerlegen der Gesamtkraft F (roter Pfeil) in die Teilkräfte Fx (grüner Pfeil) und Fz (schwarzer Pfeil) zeigt den Richtungswechsel der Kraft in Abhängigkeit von der Lageänderung der Kontaktbereiche zwischen Schiene und Zahn.

Die entstehenden Kräfte sind in ihrer Größe und ihrer Wirkungsrichtung neben der Ausdehnung der Schlitzung auch von weiteren Faktoren abhängig, wie von der Bewegungsform und -richtung sowie von der Zahnmorphologie. Aus diesem Grund lässt sich anhand der vorliegenden Studie lediglich die Tendenz herleiten, dass mit Zunahme der Schlitzung ein Kraftrichtungswechsel stattfindet. Der Übergangspunkt, an dem F=Fx ist und $\mathrm{Fz}=0$ ist, ließ sich jedoch nicht auf einen Schlitzungsgrad beziehen. Vielmehr wurde ein fließender Übergang festgestellt, sodass zum Beispiel bei den an den Zähnen 12-21 geschlitzten Schienen vereinzelt noch intrusive Kräfte gemessen wurden und bei den Schienen, die nur am Zahn 11 geschlitzt waren, bereits extrusive Kräfte auftraten.

Fraglich ist, ob die extrusiven Kräfte nur im Modellversuch auftreten oder auch in einer Patientenbehandlung mit thermoplastisch geformten Schienen. Bei den in-vitro-Versuchen wird der Zahn zunehmend ausgelenkt, in der Natur steht er bereits ausgelenkt und wird durch die Passungsdifferenz, die in die Schiene eingearbeitet ist, bewegt. Jedoch ist eine 
vergleichbare Situation denkbar, da die Umkehrung der Kraft durch die Morphologie der Palatinalfläche bedingt ist und diese Situation unabhängig vom Modellversuch auch in der Natur vorliegt.

In klinischen Studien wurden im Laufe einer Behandlung mit thermoplastisch geformten Schienen unerwünschte Intrusionen festgestellt (BREZNIAK 2008), die möglicherweise durch eine Schlitzung der Schiene vermieden oder reduziert werden könnten, wenn die Ergebnisse der vorliegenden Studie bezüglich der festgestellten Umkehrung der Kraftrichtung mit Zunahme der Schlitzgröße berücksichtigt werden. Um die Frage zu klären, ob und inwieweit die gemessenen extrusiven Kräfte für eine Behandlung von Vorteil sein könnten und ob diese auch bei größeren Auslenkungsstrecken auftreten, wären weitere Untersuchungen erforderlich und wünschenswert.

\subsubsection{Betrachtung der gemessenen Kräfte in Abhängigkeit der Kipprichtung}

Bei der Betrachtung der Kräfte in Abhängigkeit von der Kipprichtung war zu erkennen, dass die Bewegungsrichtung einen Einfluss auf die abgegebene Kraft hatte und dass die Kräfte unabhängig von der Kipprichtung mit Zunahme der Schlitzgröße abnahmen. Die Kräfte waren bei der Kippung nach vestibulär (Fx: 1,72 N - 5,41 N, Fz: -0,35 N - -2,55 N) stets etwas höher als bei der Kippung nach palatinal (Fx 1,48 N - 4,03 N, Fz: -0,02 N - 0,51 N).

Da sowohl Fx vestibulär $>$ Fx palatinal ist als auch Fz vestibulär $>$ Fz palatinal ist, ist es wahrscheinlich, dass die horizontale Querschnittsform der Schiene den Kraftunterschied verursacht. Bei der Betrachtung der Schiene von oben hat sie die Form einer Parabel. Bei der Kippung des Zahnes nach vestibulär kommt es zu einer anderen Verformung als bei der Kippung nach palatinal. Bei der Bewegung nach vestibulär wird das Schienenmaterial unter Zug belastet. Da es sich hierbei um ein Material mit geringer Elastizität handelt, führt dies schon bei geringer Auslenkung zu einer relativ hohen Kraft. Bei der Kippbewegung nach palatinal kann die palatinale Wand einer geschlitzten Schiene leichter wegkippen und verbogen werden. Dies führt regelmäßig, wie in den Ergebnissen deutlich wird, zu geringeren Kräften bei palatinaler Kippung des Messzahnes. Die Ursache der einheitlich höheren Messergebnisse bei der Kippung nach vestibulär ist demzufolge wahrscheinlich auf die geometrischen Phänomene, den gesamten Schienenkörper betreffend, zurückzuführen. 


\subsubsection{Die klinische Bedeutung der gemessenen Kraftgrößen}

In der Literatur lassen sich unterschiedliche Angaben bezüglich der optimalen Kraft für kieferorthopädische Therapien finden (SCHWARZ 1931, SCHWARZ 1932, OPPENHEIM 1942, ReitAn 1964, ReitAn 1967, BuCK und ChurCh 1972, StOREy 1973, RYGH 1976, Holtgrave 1990). Anfänglich wurden große kontinuierliche Kräfte für die Therapie verwendet. OPPENHEIM (1942) hingegen war der Meinung, dass kleine intermittierende Kräfte, die über einen längeren Zeitraum wirken, die besten Ergebnisse erzielen. HALDERSON et al. (1952) sprachen sich dagegen zwar nicht für intermittierende Kräfte aus, hielten aber kontinuierliche, jedoch sehr schwache Kräfte für günstig. Basierend auf histologischen Untersuchungen wurden in den 1950er und 1960er Jahren zunehmend Forderungen nach kleinen Kräften laut. Für die Kippung an Zähnen mit größeren Wurzeloberflächen wurden demnach Kräfte zwischen 0,5 N-0,75 N empfohlen und für Zähne mit kleineren Wurzeloberflächen Kräfte von 0,2 N - 0,3 N (REITAN 1957, REITAN 1960, REITAN 1964, REITAN 1967). SCHOPf (2000) hielt für die Initialphase einer Therapie mit Multibandapparaturen kontinuierliche Kräfte von $0,2 \mathrm{~N} / \mathrm{cm}^{2}-0,3 \mathrm{~N} / \mathrm{cm}^{2}$ Wurzeloberfläche für sinnvoll, da in diesem Fall der Druck nicht größer ist als der kapilläre Blutdruck. Laut PROFFIT (2000) sind folgende Kraftbereiche als ideal anzusehen: große Kräfte für körperliche Bewegungen $(0,70 \mathrm{~N}-1,20 \mathrm{~N})$, mittlere Kräfte für Kippung und Extrusion $(0,35 \mathrm{~N}-0,60 \mathrm{~N})$ sowie geringe Kraftgrößen für Intrusion $(0,10 \mathrm{~N}$ $-0,20 \mathrm{~N})$. Welche Werte für welche Zähne geeignet sind, hängt jeweils von der Größe des zu bewegenden Zahnes ab: Geringere Kraftgrößen sind für Schneidzähne geeignet, größere Kräfte dagegen eher für mehrwurzelige Zähne.

In der vorliegenden Arbeit wurden je nach Schlitzung horizontale Kräfte zwischen 1,48 N und 5,41 N (z0: 2,56 N - 5,41 N; z11: 1,94 N - 4,07 N; z12-21: 1,48 N - 2,09 N) gemessen. Beim Vergleich der Kräfte mit den Werten, die von PROFFIT (2000) zur Kippung von Frontzähnen als ideal angegebenen wurden, fällt auf, dass die gemessenen Kräfte eine wesentlich größere Spanne aufwiesen und vier bis neun Mal höher waren.

Die gemessenen vertikale Kräfte lagen abhängig von der Größe der Schlitzung zwischen -0,02 $\mathrm{N}$ und $-2,55 \mathrm{~N}(\mathrm{z} 0:-0,02 \mathrm{~N}--2,55 ; \mathrm{z} 11: 0,1 \mathrm{~N}--0,69 \mathrm{~N} ; \mathrm{z} 12-21: 0,20 \mathrm{~N}-0,51 \mathrm{~N})$. Beim Vergleich mit den von PROFFIT (2000) benannten Kräften lassen sich unabhängig von der Schlitzung Werte finden, die gleich groß waren wie die, die als ideal angegeben wurden, aber auch Werte, die bis um das zehnfache größer waren. Bei der Kippung nach palatinal wechselten die schwach intrusiven Kräfte $(\mathrm{Fz})$ der ungeschlitzten Schienen zu einer ansteigenden extrusiven Kraft mit zunehmender Schlitzgröße. PROFFIT (2000) hat für 
Extrusionen Kräfte zwischen 0,35 N - 0,60 N empfohlen. Im Vergleich dazu ließen sich die hier als Nebeneffekt nachgewiesenen extrusiven Kräfte in der Spanne, die als ideal angegeben wurde, für die am Zahn $11(-0,58 \mathrm{~N}--0,69 \mathrm{~N})$ und an den Zähnen $12-21(-0,35 \mathrm{~N}--0,48 \mathrm{~N})$ geschlitzten Schienen, finden.

Durch die Messungen konnte zwar gezeigt werden, dass sich je nach Schlitzgröße die Kraft bis um die Hälfte reduzieren ließ, jedoch konnten nur vereinzelt Werte gemessen wurden, die den in der Literatur als ideal ausgewiesenen entsprachen. Aufgrund dessen muss theoretisch ein erhöhtes Risiko von unerwünschten Nebenwirkungen in Betracht gezogen werden. Kommen bei kieferorthopädischen Behandlungen zu starke Kräfte zur Anwendung, kann es zu Nekrosen im Parodontalligament kommen und als Folge könnten unerwünschte Nebenwirkungen wie Wurzelresorptionen und Hyalinisation beobachtet werden (KRISHNAN und Davidovitch 2006). Da das Auftreten von Nebenwirkungen durch die gemessenen Kräfte jedoch nicht im Fokus der vorliegenden Studie stand, wird dieser Aspekt hier nur theoretisch diskutiert.

Bisher ließ sich keine eindeutige Aussage treffen, ob und in wieweit bei der Therapie mit Schienen Wurzelresorptionen auftreten (BARBAGALLO et al. 2008a, BREZNIAK und WASSERSTEIN 2002). Tendenziell wurden jedoch bei der Behandlung mit herausnehmbaren Apparaturen, zu denen auch Schienen zählen, weniger Wurzelresorptionen nachgewiesen als bei der Therapie mit festsitzenden Geräten (LINGE und LINGE 1983, GöZ und RAKOSI 1989, ACAR et al. 1999).

Diese Feststellung könnte darauf zurückgeführt werden, dass neben der Kraftgröße auch die Strecke, über die eine Kraft wirkt, entscheidend für das Ausmaß der auftretenden Nebenwirkungen ist. Bei der Schienentherapie werden die Zähne im Vergleich zur Behandlung mit Multiband durch eine in das Setup eingearbeitete definierte Strecke bewegt. Die Kraftgröße könnte von untergeordnetem Interesse sein, wenn die eingearbeitete Aktivierungsstrecke geringer oder gleich der Weite des Parodontalspaltes ist, die zwischen 0,1 $\mathrm{mm}$ und 0,3 mm beträgt (COOLIDGE 1937, SCHROEDER 1986). So würde es zu keiner vollständigen Unterbrechung der Blutzirkulation kommen und Nebenwirkungen wären theoretisch ausgeschlossen (HAHN 2009).

In der Literatur lassen sich unterschiedliche Empfehlungen bezüglich der Aktivierungsstrecken für die Zahnumstellung bei Schienentherapie finden. Einige Autoren sprachen von $0,15 \mathrm{~mm}$ bis $0,25 \mathrm{~mm}$ (VLASKALIC et al. 2001, FALTIN et al. 2003, GiANCOTTI et al. 2006), andere von 0,25 mm bis 0,33 mm (BOYD et al. 2000, OWEN 2001, JOFFE 2003). 
In einer Studie aus dem Jahr 2008 wurden Auslenkungsstrecken von 0,2 mm bis 0,5 mm als optimal empfunden (KWON et al. 2008). BARBAGALLO et al. (2008b) verwendeten eine Auslenkungsstrecke von 0,5 mm. Für die vorliegende Arbeit wurde eine Auslenkungsstrecke von $\pm 0,151 \mathrm{~mm}$ gewählt, die im Vergleich zu denen in der Literatur angegebenen Werten nur ca. halb so groß war. Bis auf die Auslenkungsstrecke von 0,5 mm (BARBAGALLO et al. 2008b) liegen sowohl die verwendete als auch die in der Literatur angegebenen Auslenkungsstrecken in der Breite des Parodontalspaltes. Aufgrund dessen käme es mit den verwendeten Schienen nicht zur Einengung des Parodontalspaltes, so dass die gemessenen Kraftgrößen in diesem Zusammenhang vernachlässigt werden könnten.

Des Weiteren wurde bei den Messungen dieser Studie ein Abheben der Schiene in Relation zur Bewegung beobachtet, wie es bereits in anderen Studien mit gleichen $( \pm 0,151 \mathrm{~mm})$ oder größeren Auslenkungsstrecken ( $\pm 0,8 \mathrm{~mm}$ ) beschrieben wurde (HAHN et al. 2009a, HAHN et al. 2009b, HAHN et al. 2010b). Durch das Abheben wird die eingearbeitete Auslenkungsstrecke nicht vollständig wirksam. Dies könnte als eine Art Selbstschutzmechanismus interpretiert werden, der bei größeren Auslenkungsstrecken zunehmend deutlicher wirksam wird und eine Überbelastung verhindert und somit vor Nebenwirkungen schützt (HAHN et al. 2009 a, HAHN et al. 2009b, HAHN et al. 2010a, HAHN et al. 2010b).

\subsubsection{Vergleich mit Kraftmessungen an Schienen anderer Materialien und bei anderen Bewegungsformen}

HAHN et al. (2010b) haben die Kraftabgabe von thermoplastischen Schienen bei simulierten Torquebewegungen eines oberen mittleren Frontzahnes untersucht. Dabei haben sie für Fx Kräfte zwischen 0,11 N und -1,89 N gemessen und für Fz Kräfte zwischen -0,07 N und -0,97 N. Der Vergleich der Werte, die in der vorliegenden Arbeit gemessen wurden, und der von HAHN et al. (2010b) dokumentierten Werte zeigte ähnliche Kraftgrößen für die intrusiven Kräfte (Fz) für die am Zahn 11 geschlitzten Schienen (-0,58 N - -0,68 N) und für die an den Zähnen 12-21 geschlitzten Schienen (-0,32 N - -0,48 N) bei vestibulärer Auslenkung. Für die horizontalen Kräfte (Fx) ließen sich Vergleichswerte nur für die an den Zähnen 12-21 geschlitzten Schienen (1,48 N - 2,09 N) finden.

Die Kräfte entstehen bei Torquebewegungen im Bereich der marginalen Gingiva. Hier ist die Schiene weniger versteift als inzisal. Bei der Kippbewegung entstehen die Kräfte im Schienenbereich mit der stärksten Krümmung, also an der Inzisalkante (HAHN 2009). Durch 
die Schlitzung wurde, wie oben beschrieben (vgl. Kapitel 4.2.1), die Versteifung an der Inzisalkante verändert. Aufgrund der Ähnlichkeit der Ergebnisse zu den Messungen von HAHN et al. (2010b) könnte angenommen werden, dass bei den geschlitzten Schienen vergleichbare Kraftverhältnisse vorlagen wie im Bereich des marginalen Schienenrandes. Erkennbar war, dass eine einzelne Schlitzung am Zahn 11 nicht ausreichte, um den Versteifungseffekt ausreichend aufzuheben und Werte für Fx zu erhalten, wie sie im Bereich der marginalen Gingiva gemessen wurden. Diese lagen nach wie vor zwischen 1,94 N - 4,07 $\mathrm{N}$ und waren damit deutlich höher als die von HAHN et al. (2010b) für die Torquebewegung gemessenen Kräfte. Demzufolge ist eine größere Schlitzung nötig, um eine ausreichende Flexibilität der Schienen zu erreichen und um dadurch wiederum Kraftverhältnisse wie marginal zu erhalten.

WARUNEK et al. (1989) führten Modellversuche an einem einzelnen mittleren Oberkieferschneidezahn durch, wobei sie Positioner aus verschiedenen Materialien verwendeten. Die Bewegungsstrecken betrugen zwischen 0,5 $\mathrm{mm}$ und 2,5 $\mathrm{mm}$ und waren damit drei- bis siebzehnfach größer als die in dieser Studie verwendete Strecke $( \pm 0,151 \mathrm{~mm})$. Bei der kleinsten Auslenkung haben WARUNEK et al. (1989) Kräfte zwischen $1 \mathrm{~N}$ und $4 \mathrm{~N}$ gemessen, bei der größten Strecke Kräfte von 2 N bis 15 N. Damit waren die Werte insgesamt höher als die von PROFFIT (2000) als ideal angegebenen. Vergleicht man die Ergebnisse für Fx aus der vorliegenden Studie mit den Werten von WARUNEK et al. (1989) für die kleinen Auslenkungsstrecken, finden sich Ergebnisse in einer ähnlichen Spanne (z0: 2,56 N-5,41 N; z11: 1,94 N-4,07 N; z12-21: 1,48 N-2,09 N). Auch bei den größeren Auslenkungsstrecken lassen sich vereinzelt Kräfte finden, die ähnlich groß waren. Zum Teil waren sie jedoch 3- bis 71/2-fach größer. Zusammenfassend ist erkennbar, dass trotz der größeren Auslenkungsstrecken, die WARUNEK et al. (1989) verwendeten, zum Teil vergleichbare Werte gemessen wurden.

Ursächlich dafür sind die Unterschiede in den Materialeigenschaften: In den Untersuchungen von WARUNEK et al. (1989) wurden Elastomere verwendet, die zu den „weichen Kunststoffen“ zählen. In der vorliegenden Studie wurden „harte Kunststoffe“ verwendet. Die Kraftabgabe ist also auch von den Materialeigenschaften (ROST et al. 1993) wie z. B von der Größe des Elastizitätsmoduls eines Materials abhängig. Der Elastizitätsmodul variiert je nach Material. Es beschreibt den Zusammenhang zwischen der Dehnung und Spannung eines Materials bei seiner Verformung (MARXKORS et al. 2008). Je mehr Widerstand ein Material 
seiner Verformung entgegenbringt, desto größer ist der E-Modul $\left(E=\frac{\sigma}{\varepsilon}\right.$ mit $\sigma=$ mechanische Spannung und $\varepsilon=$ Dehnung. Die Einheit ist Pascal). Ein Material mit hohem EModul ist also steifer als ein Material mit tiefem E-Modul. Folglich erzeugen thermoplastisch geformte Schienen mit einem großen E-Modul bei gleicher Schienendicke größere Kräfte als Schienen mit niedrigem E-Modul.

Ist die Auslenkungsstrecke gleich groß, sind die Kräfte ebenfalls umso höher, je größer der EModul des Materials. Ist die Steifigkeit des Materials gleich und sind die Auslenkungsstrecken unterschiedlich, so steigen die Kräfte mit der Größe der Auslenkungsstrecke. Deshalb können bei so geringen Auslenkungsstrecken, wie sie in der vorliegenden Studie verwendet wurden, mit härteren Materialien vergleichbar hohe Kräfte erzeugt werden wie bei größeren Auslenkungsstrecken mit weicheren Materialien, wie in den Versuchen von WARUNEK et al. (1989).

Eine vergleichbare Studie wurde 1995 von Rost et al. (1995) publiziert. Sie untersuchten die Kraftabgabe von Positionern aus sieben verschiedenen Materialien auf die Oberkieferschneidzähne. Ziel war es, die Abhängigkeit der Kraftgröße zum einen vom Material und zum anderen vom Ausmaß der Protrusion zu ermitteln. Die in der Studie von Rost et al. (1995) verwendeten Materialien wiesen eine unterschiedliche Steifigkeit auf. Es wurden Kräfte zwischen 0,4 N und $14 \mathrm{~N}$ gemessen, bei den Auslenkungsstrecken 0,25 mm, $0,5 \mathrm{~mm}$ und $1 \mathrm{~mm}$. Vereinzelt wurden Kräfte gemessen, die den von ProfFIT (2000) als optimal angegebenen und den in der vorliegenden Studie gemessenen Kräfte (z0: 2,56 N 5,41 N; z11: 1,94 N-4,07 N; z12-21: 1,48 N - 2,09 N) entsprachen. Als ursächlich dafür kann erneut die Abhängigkeit zwischen Materialsteifigkeit und Größe der Auslenkungsstrecke benannt werden. In Gänze betrachtet waren jedoch bei RosT et al (1995) wie auch bei WARUNEK et al. (1989) die Kräfte im Vergleich zu ProfFIT (2000) und zu den Ergebnissen der vorliegenden Studie $\mathrm{zu}$ hoch, was im Wesentlichen auf die sehr großen Auslenkungsstrecken zurückzuführen ist.

KWON et al. (2008) stellten in ihrer Studie Proben aus drei verschiedenen thermoplastischen Materialien unterschiedlicher Dicke $(0,5 \mathrm{~mm}, 0,8 \mathrm{~mm}$ und $1 \mathrm{~mm})$ im Vakuumverfahren her. Anstelle eines Zahnkranzes wurde ein Modell in Form eines flachen Steins verwendet. Mit dem verwendeten Drei-Punkt-Biegeversuch beabsichtigten sie, die Kippung eines oberen Frontzahnes durch Schienenmaterialien zu simulieren. Sie verwendeten Bewegungsstrecken zwischen 0,2 $\mathrm{mm}$ und $2 \mathrm{~mm}$ und ermittelten je nach Auslenkungsstrecke für alle Materialien 
Kräfte zwischen 0,05 $\mathrm{N}$ und $16 \mathrm{~N}$. Bei der Bewegungsstrecke von 0,2 mm und einer Materialstärke von $1 \mathrm{~mm}$ ermittelten sie Kräfte zwischen 0,055 N und 0,916 N (KwON et al. 2008). Die in der vorliegenden Arbeit verwendete Auslenkungsstrecke ist mit $\pm 0,151 \mathrm{~mm}$ nur um 1/4 kleiner als die kleinste von KWON et al. (2008) verwendete Strecke und somit annähernd vergleichbar. Die bei ähnlicher Auslenkungsstrecke gemessenen Werte für Fx in der vorliegenden Untersuchung waren je nach Material und Schlitzung zwei- bis fünffach größer (Fx z0: 2,56 N - 5,51 N; z11: 1,94 N - 4,07 N; z12-21: 1,48 N - 2,09 N) als der höchste Wert $(0,916 \mathrm{~N})$ aus der Vergleichsstudie (KWON et al. 2008) bei entsprechender Strecke.

Wie oben beschrieben (vgl. Kapitel 4.2.1), zeichnen sich thermoplastisch geformte Schienen nach dem Tiefziehprozess durch komplexe geometrische Formen aus. Die über einen flachen Stein gezogenen Folien sind jedoch gerade und weisen dadurch keine Versteifungseffekte auf. Demzufolge waren die daran entstandenen Kräfte geringer als bei den thermoplastisch geformten Schienen. Durch die Schlitzung wurde die Versteifung, die durch den Herstellungsprozess entsteht (vgl. Kapitel 4.2.1), in der vorliegenden Studie zwar teilweise aufgehoben, jedoch lagen nach wie vor grundsätzlich andere geometrische Formmerkmale vor als bei den flachen Proben. Aufgrund dieser Unterschiede scheint der Vergleich mit den flachen Proben bezogen auf die Kraftentstehung von thermoplastischen Schienen ungeeignet.

In einer weiteren in-vivo Studie (BARBAGALlO et al. 2008b) wurden Kippbewegungen in vestibulärer Richtung an einem ersten oberen Prämolaren mit thermoplastischen Schienen aus Erkodur $^{\circledR} 0,8 \mathrm{~mm}$ durchgeführt. In jede Apparatur wurde eine Bewegungsstrecke von 0,5 mm eingearbeitet. BARBAGALLO et al. (2008b) verwendeten für die Versuche druckempfindliche Folien mit Farbindikator (Pressurex ${ }^{\circledR}$, Fuji Photo Film Co., Ltd, Tokyo, Japan). Die Folie änderte druckabhängig die Farbe, woraus sich Rückschlüsse auf die applizierte Kraft ziehen ließen. Es ergab sich eine Anfangskraft von 5,12 N, die innerhalb der zweiwöchigen Tragedauer linear abnahm (BARBAGALLO et al. 2008b).

Die Ergebnisse von BARBAGALlo et al. (2008b) waren im Vergleich zu denen in der Literatur als ideal angegebenen Kräften (PROFFIT 2000) um ein vielfaches zu hoch. Bei der Betrachtung der Ergebnisse aller Materialien in der vorliegenden Studie ließen sich Vergleichswerte zu den initialen Kräften (5,12 N) von BARBAGALlO et al. (2008b) nur bei den gemessenen horizontalen Kräften (Fx) der ungeschlitzten Schienen (Fx: 2,56 N - 5,41 N) finden. Für die am Zahn 11 geschlitzten Schienen (Fx:1,94 N - 4,07 N) und für die an den Zähnen 12-21 geschlitzten Schienen (Fx: 1,48 N - 2,07 N) waren die Kräfte 1/2 bis 3/4 kleiner als der Vergleichswert. Die gemessenen intrusiven und extrusiven Kräfte waren, abhängig von der 
jeweiligen Schlitzung, um ein vielfaches niedriger (Fz0: -0,02 N - -2,55 N; Fz z11: 0,1 N $-0,69 \mathrm{~N} ;$ Fz z12-21: 0,26 N - 0,51 N).

Dass die Kräfte bei BARBAGALlo et al. (2008b) im Vergleich zu den in der vorliegenden Studie gemessenen Kräften höher ausfallen, kann unterschiedliche Ursachen haben: Zum einen könnte dies darin begründet sein, dass bei der Verwendung von Pressurex ${ }^{\circledR}$-Folien keine präzise Trennung der horizontalen und intrusiven Kraftkomponenten erfolgen kann. Deshalb ist es fraglich, inwieweit die Werte die kippenden Kräfte wiedergeben (ENGELKE 2010). Des Weiteren führten BARBAGALlO et al. (2008b) die Untersuchungen an einem Prämolaren durch, während in der vorliegenden Studie ein Frontzahn verwendet wurde. Durch die unterschiedliche Morphologie dieser Zähne ist die Auflagefläche der Schiene bei einem Prämolaren größer als bei einem Frontzahn: Zwischen der Schiene und einem Frontzahn besteht ein Kontaktpunkt in der Nähe der Inzisalkante, während bei einem Prämolaren eine Kontaktfläche vorliegt. Daher kommt es bei der Kippung eines Prämolaren zu einer stärkeren Verformung der Schiene, wodurch unterschiedliche Spannungen entstehen und stärkere Rückstellkräfte resultieren. Somit sind bei einem Prämolaren andere biomechanische Gegebenheiten anzunehmen als bei einem Frontzahn. Des Weiteren ist denkbar, dass bei einem Prämolaren durch die vestibuläre bauchige Form der Selbstschutzmechanismus, der durch das Abheben entsteht, geringer ausgeprägt ist, weil untersichgehende Stellen existieren, die das Abheben der Schiene erschweren. Außerdem liegt ein anders geartetes okklusales Relief vor, welches eventuell einen anderen Versteifungsmechanismus bedingt.

Die in der vorliegenden Studie verwendeten Schienen wurden aus drei verschiedenen Materialien der Stärke $1 \mathrm{~mm}$ hergestellt. Bei einer Schiene aus Biolon ${ }^{\circledR}$ wurde mit 5,41 N der höchste Wert gemessen. Dieser ist vergleichbar mit dem Wert von 5,21 N, den BARBAGaLlo et al. (2008b) in ihrer Studie angeben. Wie in Kapitel 4.1 .2 bereits beschrieben, hat das unterschiedliche Schienenmaterial einen Einfluss auf die abgegebene Kraft. Beim Vergleich der Ergebnisse von BARBAGAllo et al. (2008b) und denen der vorliegenden Studie wird deutlich, dass auch die Schienenendicke einen Einfluss auf die Kraft hat. BARBAGALLO et al. (2008b) benutzten im Gegensatz zur vorliegenden Studie ausschließlich Schienen aus Erkodur $^{\circledR}$ 0,8 mm. Da sich die Kraft aus dem Multiplikator von Spannung $\sigma$ und Materialquerschnitt $A$ errechnet $\left(\mathrm{F}=\sigma^{*} \mathrm{~A}\right)$, bedeutet das bezogen auf den Durchmesser des Schienenkörpers, dass ein dickeres Material bei identischer Auslenkung (= Spannung) eine höhere Kraft generiert (ENGELKE 2010). 
Betrachtet man die gemessenen Kräfte der ungeschlitzten Erkodur ${ }^{\circledR}$-Schienen 1 mm (Fx: z0: 2,56 N - 3,11 N; z11: 1,94 N - 2,47 N; z12-21: 1,49 N - 1,75 N) in der vorliegenden Studie, fällt auf, dass diese Werte mit einer Auslenkungsstrecke $( \pm 0,151 \mathrm{~mm})$, die nur ein Drittel der Auslenkungsstrecke $(0,5 \mathrm{~mm})$ von BARBAGALlO et al. (2008b) betrug, dennoch lediglich um die Hälfte kleiner war. Dadurch wird deutlich, dass die gemessenen Kräfte abhängig sind von dem Zusammenspiel aus Materialeigenschaft (Dicke und Steifigkeit des Materials), der Auslenkungsstrecke und der Morphologie des Zahnes. Mit dünneren Materialien und größeren Auslenkungsstrecken lassen sich ähnliche Kräfte erzeugen wie mit kleineren Auslenkungsstrecken und dickeren Materialien. Abschließend lässt sich feststellen, dass aufgrund der unterschiedlichen Ausgangsbedingungen ein Vergleich zwischen der vorliegenden Studie und der Arbeit von BARBAGALLO et al. (2008b) nur eingeschränkt möglich ist. 


\section{$5 \quad$ Zusammenfassung}

Ziel dieser Studie war es, die initial auftretenden Kräfte, die von thermoplastischen Schienen verschiedener Modifikationsformen bei der Kippung eines oberen zentralen Schneidezahns in palatinaler und vestibulärer Richtung erzeugt wurden, zu ermitteln. Für die Versuche wurde eine neu entwickelte modulare in-vitro-Messapparatur verwendet.

45 Tiefziehschienen aus drei unterschiedlichen Materialien der Stärke $1 \mathrm{~mm}$ (Biolon ${ }^{\circledR}$, Erkodur $^{\circledR}$, Ideal Clear ${ }^{\circledR}$ ) wurden für die Messung verwendet. 15 Schienen wurden inzisal des Zahnes 11 geschlitzt, bei 15 weiteren Schienen wurde die Schlitzung zusätzlich zur Inzisalkante am Zahn 11 auf die beiden Nachbarzähne 12 und 21 ausgedehnt. Die restlichen Schienen blieben ungeschlitzt.

Von besonderem Interesse war, wie sich die Kraft durch die Schlitzung veränderte, welche Unterschiede sich für die einzelnen Materialien ergaben und welchen Einfluss die verschiedenen Tiefziehverfahren hatten. Die gemessenen Kräfte waren im Vergleich zu den in der Literatur als optimal ausgewiesenen (PROFFIT 2000) sowohl bei den ungeschlitzten als auch bei den geschlitzten Schienen deutlich höher. Sowohl bei den horizontalen Kräften (Fx) als auch bei den intrusiven Kräften (Fz) erfolgte aber eine Abnahme der Kraft mit Zunahme der Schlitzgröße. Es konnte festgestellt werden, dass sich durch die Schlitzung eine Reduktion der Kraft Fx um etwa die Hälfte erzielen ließ. Für Fz bei der Bewegung nach palatinal veränderten sich die Kräfte von einer schwach intrusiven Kraft bei Schienen ohne Schlitz zu einer extrusiven Kraft mit zunehmender Schlitzung. Die auftretenden extrusiven Kräfte bewegten sich in der Spanne, die in der Literatur als ideal angegeben wird (PROFFIT 2000).

Nicht für alle Messungen statistisch signifikant, aber doch tendenziell erkennbar, wiesen die Schienen aus Biolon ${ }^{\circledR}$ die höchsten Kräfte im Vergleich zu den beiden anderen Materialien auf, was mit verschiedenen Herstellungsverfahren begründbar ist.

Die vorliegenden Ergebnisse unterstreichen die Komplexität der Krafterzeugung mittels thermoplastisch geformter Schienen. Sie zeigen, dass durch einfache Modifikationen, wie z. B. eine Schlitzung inzisal, Änderungen verschiedener biomechanischer Parameter auftreten können. Zum tiefer gehenden Verständnis dieser Zusammenhänge sind jedoch weitere invitro-Studien genau wie klinische Untersuchungen notwendig. 


\section{Datenanhang}

Datentabelle zu Abbildung 8 (S.18):

\begin{tabular}{|c|c|c|c|}
\hline Winkel & $\mathrm{Fx}(\mathrm{z} 0)$ & $\begin{array}{l}\text { Fx } \\
(\mathrm{z} 11)\end{array}$ & $\begin{array}{l}\text { Fx } \\
\text { (z12-21) }\end{array}$ \\
\hline 0 & 0 & $-0,03$ & $-0,02$ \\
\hline 2,77777 & $-0,34$ & 0,35 & 0,04 \\
\hline 5,55555 & $-0,92$ & $-0,8$ & $-0,22$ \\
\hline 8,33333 & $-1,49$ & $-0,48$ & $-0,38$ \\
\hline 11,11111 & $-2,03$ & $-0,87$ & $-0,58$ \\
\hline 13,88888 & $-2,64$ & $-1,39$ & $-0,85$ \\
\hline 16,66666 & $-3,25$ & $-1,87$ & $-1,42$ \\
\hline 19,44444 & $-3,63$ & $-2,41$ & $-1,42$ \\
\hline 22,22222 & $-4,03$ & -3 & $-1,7$ \\
\hline 22,22222 & $-3,66$ & $-3,03$ & $-1,79$ \\
\hline 19,44444 & $-3,23$ & $-2,42$ & $-1,28$ \\
\hline 16,66666 & $-2,75$ & $-1,77$ & $-1,06$ \\
\hline 13,88888 & $-2,28$ & $-1,19$ & $-0,87$ \\
\hline 11,11111 & $-1,59$ & $-0,82$ & $-0,71$ \\
\hline 8,33333 & $-0,97$ & $-0,58$ & $-0,44$ \\
\hline 5,55555 & $-0,45$ & $-0,17$ & $-0,18$ \\
\hline 2,77777 & $-0,03$ & 0,2 & 0,08 \\
\hline 0 & 0,41 & 0,5 & 0,35 \\
\hline 0 & $-0,01$ & $-0,33$ & $-0,03$ \\
\hline$-2,77777$ & 0,49 & 0,26 & 0,28 \\
\hline$-5,55555$ & 1,29 & 0,82 & 0,59 \\
\hline$-8,33333$ & 2 & 1,34 & 0,86 \\
\hline$-11,11111$ & 2,73 & 1,82 & 1,07 \\
\hline$-13,88888$ & 3,34 & 2,37 & 1,3 \\
\hline$-16,66666$ & 4 & 3 & 1,55 \\
\hline$-19,44444$ & 4,71 & 3,56 & 1,81 \\
\hline$-22,22222$ & 5,41 & 4,07 & 2,09 \\
\hline$-22,22222$ & 5,28 & 3,88 & 1,91 \\
\hline$-19,44444$ & 4,61 & 3,15 & 1,53 \\
\hline$-16,66666$ & 3,85 & 2,63 & 1,19 \\
\hline$-13,88888$ & 3,02 & 2,13 & 0,91 \\
\hline$-11,11111$ & 2,7 & 1,61 & 0,64 \\
\hline$-8,33333$ & 1,73 & 1,16 & 0,5 \\
\hline$-5,55555$ & 0,87 & 0,77 & 0,28 \\
\hline$-2,77777$ & 0,22 & 0,7 & 0,24 \\
\hline 0 & $-0,42$ & 0,35 & $-0,05$ \\
\hline
\end{tabular}

Tabelle 12: Die ermittelten Kräfte Fx für die jeweilige Schlitzung bei dem entsprechenden Winkel für die palatinale und die vestibuläre Auslenkung für das Material Biolon ${ }^{\circledR} 1 \mathrm{~mm}$. 


\section{$7 \quad$ Literaturverzeichnis}

Acar A, Canyürek U, Kocaaga M, Erverdi N (1999): Continous vs. discontinuous force application and root resorption. Angle Orthod $\underline{69}, 159-164$

Andreasen GF, Zwanziger D (1980): A clinical evaluation of the differential force concept as applied to the edgewise bracket. Am J Orthod $\underline{78}, 25-40$

Apajalahti S, Peltola JS (2007): Apical root resorption after orthodontic treatment-a retrospective study. Eur J Orthod 29, 408-412

Baccetti T, Franchi L, Camporesi M (2008): Forces in the presence of ceramic versus stainless steel brackets with unconventional vs conventional ligatures. Angle Orthod $\underline{78}$ (1), 120-124

Barbagallo LJ, Jones AS, Petocz P, Darendeliler MA (2008 a): Physical properties of root cementum: Part 10. Comparison of the effects of invisible removable thermoplastic appliances with light and heavy orthodontic forces on premolar cementum. A microcomputed-tomography study. Am J Orthod Dentofacial Orthop 133(2), 218-227

Barbagallo LJ, Shen G, Jones AS, Swain MV, Petocz P, Darendeliler MA (2008 b): A Novel Pressure Film Approach for Determining the Force Imparted by Clear Removable Thermoplastic Appliances. Ann Biomed Eng $\underline{36}$ (2), 335-341

Bartzela TN, Senn C, Wichelhaus A (2007): Load-deflection characteristics of superelastic nickel-titanium wires. Angle Orthod 77(6), 991-998

Bollen A-M, Huang G, King G, Hujoel P, Ma T (2003): Activation time and material stiffness of sequential removable orthodontic appliances. Part 1: Ability to complete treatment. Am J Orthod Dentofacial Orthop 124(5), 496-501

Boyd RL, Vlaskalic V (2001): Three dimensional diagnosis and orthodontic treatment of complex malocclusions with the Invisalign appliance. Sem Orthod $\underline{7}$ (4), 274-293 
Boyd RL, Miller RJ, Vlaskalic V (2000): The Invisalign system in adult orthodontics: Mild crowding and space closure cases. J Clin Orthod $\underline{34}$ (4), 203-212

Brezniak N (2008): The clear plastic appliance: a biomechanical point of view. Angle Orthod $\underline{78}, 381-382$

Brezniak N, Wasserstein A (2002): Orthodontically induced inflammatory root resorption. Part I: The basic science aspects. Angle Orthod $\underline{72}$, 175-179

Buck DL, Church DH (1972): A histologic study of human tooth movement. Am J Orthod $\underline{62}$, 507-516

Burstone CJ, Pryputniewicz RJ (1980): Holographic determination of centers of rotation produced by orthodontic forces. Am J Orthod 77, 396-409

Burstone CJ, Pryputniewicz RJ (1981): Centers of resistance of the human mandibular molars. J. Dent. Res. $\underline{60}, 515$

Casa Ma, Faltin RM, Faltin K, Sander FG, Arana-Chavez VE (2001): Root resorptions in upper first premolars after application of continuous torque moment. $\mathrm{J}$ Orofac Orthop/Fortschr Kieferorthop $\underline{62}$, 285-295

Cattaneo PM, Dalstra M, Melsen B (2008): Moment-to-force ratio, center of rotation, and force level: a finite element study predicting their interdependency for simulated orthodontic loading regimens. Am J Orthod Dentofacial Orthop 133 (5), 681-689

Clements KM, Bollen AM, Huang G, King G, Hujoel P, Ma T (2003): Activation time and material stiffness of sequential removable orthodontic appliances. Part 2: dental improvements. Am J Orthod Dentofacial Orthop 124 (5), 502-508

Coolidge E (1937): The thickness of the human periodontal membrane. J Am Dent Assoc 24, $1260-1265$ 
Djeu G, Shelton C, Maganzini A (2005): Outcome assessment of invisalign and traditional orthodontic treatment compared with the american board of orthodontics objective grading system. Am J Orthod Dentofacial Orthop 128, 292-298

Dorow C, Sander FG (2005): Development of a model for the simulation of orthodontic load on lower first premolars using the finite element method. J Orofac Orthop $\underline{66}$, 208-218

Engelke B (2010): Kraft- und Drehmomentabgabe thermoplastisch geformter Schienen bei Frontzahnderotation vor und nach Alterungssimulation. Med. Diss. Göttingen 2010

Faltin RM, Arana-Chavez VE, Faltin K, Sander FG, Wichelhausen A (1998): Root resorption in upper first premolars after application of continuous intrusive forces. Intra-individual study. J Orofac Orthop/ Fortschr Kieferorthop 59, 208-219

Faltin RM, de Almeida MAA, Kessner CA, Faltin K (2003): Efficiency, three-dimensional planning and prediction of the orthodontic treatment with the Invisalign ${ }^{\circledR}$ System: case report. R Clin Ortodon Dental Press $\underline{31}$, 297-304

Farrar JN (1876): An inquiry into physiological and pathological changes in animal tissues in regulating teeth. Dent Cosmos $\underline{18}(1), 13-24$

Giancotti A, Greco M, Mampieri G (2006): Extraction treatment using Invisalign ${ }^{\circledR}$ Technique. Prog Orthod $\underline{7}$ (1), 32-43

Göz G (2010): Stellungnahme der DGKFO zur Behandlung mit Alignern.

Göz G, Rakosi Th (1989): Die apikale Wurzelresorption unter kieferorthopädischer Behandlung. Fortschr Kieferorthop 50, 196-206

Häupl K: Gewebsumbau und Zahnverdrängung in der Funktions-Kieferorthopädie. Eine funktionell - histologische Studie. Barth, Leipzig 1938

Hahn W (2009): Kraft-Drehmomentabgabe und Biomechanik thermoplastisch geformter Schienen zur orthodontischen Zahnbewegung. Med. Habilitationschrift Göttingen 2009 
Hahn W, Dathe H, Fialka-Fricke J, Fricke-Zech S, Zapf A, Kubein-Meesenburg D, SadatKhonsari R.(2009a): Influence of thermoplastic appliance thickness on the magnitude of force delivered to a maxillary central incisor during tipping. Am J Orthod Dentofacial Orthod $\underline{136}(1), 12 . \mathrm{e} 1-7$

Hahn W, Fialka-Fricke J, Dathe H, Fricke-Zech S, Zapf A, Gruber R, Kubein-Meesenburg D, Sadat-Khonsari R. (2009b): Initial forces generated by three types of thermoplastic appliances on an upper central incisor during tipping. Eur J Orthod $\underline{31}$ (6), 625-631

Hahn W, Engelke B, Jung K, Dathe H, Fialka-Fricke J, Kubein-Meesenburg D, SadatKhonsari R (2010a): Initial forces and moments delivered by removable thermoplastic appliances during rotation of an upper central incisor. Angle Orthod $\underline{80}$ (2), 239-246

Hahn W, Zapf A, Dathe H, Fialka-Fricke J, Fricke-Zech S, Gruber R, Kubein-Meesenburg D Sadat-Khonsari R (2010b): Torquing an upper central incisor with aligners-acting forces and biomechanical principles. Eur J Orthod $\underline{32(6), 607-613}$

Hahn W, Engelke B, Jung K, Dathe H, Kramer FJ, Rödig T, Kubein-Meesenburg D, Gruber RM (2011): The influence of occlusal forces on force delivery properties of aligners during rotation of an upper central incisor. Angle Orthod $\underline{81}(6), 1057-1063$

Halderson H, Johns EE, Moyers R (1952): The selection of forces for tooth movement. Am J Orthod $\underline{39}, 25-35$

Harris DA, Jones AS, Darendeliler MA (2006): Physical properties of root cementum: Part 8. Volumetric analysis of root resorption craters after application of controlled intrusive light and heavy orthodontic forces: A microcomputed tomography scan study. Am J Orthod Dentofac Orthop $\underline{130}$ (5), 639-47

Harzer W: Lehrbuch der Kieferorthopädie. Hanser Verlag; München, Wien 1999

Hixon EH, Aasen TO, Aranzo J, Clark Ra, Klosterman R, Miller SS, Odom WM (1970): On force and tooth movement. Am J Orthod $\underline{57}$, 476-489 
Holtgrave E-A (1990): Die Bedeutung des gingivalen Fasersystems für die kieferorthopädische Zahnbewegung - Eine tierexperimentelle Untersuchung. Fortschr Kieferorthop 51, 90-98

Hotz R (1967): Wurzelresorption an bleibenden Zähnen. Fortschr Kieferothop 28, 217-224

http://www.schunk.com/schunk_files/attachments/FT-Nano_17_DE.pdf

Hurd, J J, Nikolai R J (1976): Centers of rotation for combined vertical and transverse tooth movements. Am J Orthod $\underline{70}, 551-558$

Joffe L (2003): Current Products and Practice. Invisalign ${ }^{\circledR}$ : early experiences. J Orthod $\underline{30}$, $348-352$

Kahl-Nieke B : Einführung in die Kieferorthopädie. 2., neu bearbeitete Auflage. Urban \& Fischer Verlag München Jena 2001

Kesling HD (1945): The philosophy of the tooth positioning appliance. Am J Orthod $\underline{31}$ (6), 297-304

Krämer (2010): Optimierung und Anwendung eines Systems zur Applikation von 3-DKräften und Drehmomentne im Drei-Bracket-Modell. Med. Diss. Freiburg i. Br. 2010

Kravitz ND, Kusnoto B, Agran B, Viana G (2008): Influence of attachments and interproximal reduction on the accuracy of canine rotation with invisalign. Angle Orthod $\underline{78}$ (4), 682-687

Krishnan V, Davidovitch Z (2006): Cellular, molecular, and tissue-level reactions to orthodontic force. Am J Orthod Dentofacial Orthop 129(4), 469.e, 1-460 e.32

Kwon JS, Lee JK, Lim BS, Lim YK (2008): Force delivery properties of thermoplastic orthodontic materials. Am J Orthod Dentofacial Orthop 133 (2), 228-234 
Lagravère MO, Flores-Mir C (2005): The treatment effects of Invisalign orthodontic aligners: a systematic review. J Am Dent Assoc 136(12), 1724-1729

Lapatki BG, Paul O (2007): Smart brackets for 3D-force-moment measurements in orthodontic research and therapy - developmental status and prospects. J Orofac Orthop $\underline{68}$ (5), 377-396

Lapatki BG, Bartholomeyczik J, Ruther P, Jonas IE, Paul O (2007): Smart bracket for multidimensional force and moment measurement. J Dent Res $\underline{86}$ (1), 73-78

Levander E, Malmgren O (1988): Evaluation of the risk of root resorption during orthodontic treatment: a study of upper incisors. Eur J Orthod $\underline{10}, 30-38$

Lim Y, Quick A, Swain M, Herbison P (2008): Temperature Effects on the Forces, Moments and Moment to Force Ratio of Nickel-Titanium and TMA Symmetrical T-loops. Angle Orthod $\underline{78}$ (6), 1035-1042

Lindauer SJ, Shoff RC (1998): Comparison of Essix and Hawley retainers. J Clin Orthod $\underline{32}$, 95-97

Linge BO, Linge L (1983): Apical root resorption in upper anterior teeth. Eur J Orthod $\underline{5}$, $173-183$

Maltha JC, Kuijpers-Jagtman AM, Pilon JJ (1993): Relation between force magnitude and orthodontic tooth movement. Eur J Orthod $\underline{15}, 452$

Maltha JC, van Leeuwen EJ, Kuijpers-Jagtman AM (1995): Tissue reaction to light orthodontic forces. Abstracts of lectures. Eur J Orthod 17, 329-53

Maltha JC, van Leeuwen EJ, Dijkman GEHM, Kuijpers-Jagtman AM (2004): Incidence and severity of root resorption in orthodontically moved premolars in dogs. Orthod Craniofac Res 7, $115-21$ 
Marxkors R, Meiners H, Geis-Gerstorfer J: Taschenbuch der zahnärztlichen Werkstoffkunde. Vom Defekt zur Restauration. 6. Auflage, Deutscher Zahnärzte Verlag, Köln 2008

Meier B, Wiemer KB, Miethke RR (2003): Invisalign ${ }^{\circledR}$-Patient profiling. Analysis of a prospective survey. J Orofac Orthop $\underline{64}, 352-358$

Nakamura Y, Noda K, Shimoda S, Oikawa T, Arai C, Nomura Y, Kawasaki K (2008): Timelapse observation of rat periodontal ligament during function and tooth movement, using microcomputed tomography. Eur J Orthod 30(3), 320-326

Natali A, Pavan P, Carniel E, Dorow C (2004): Viscoelastic response of the periodontal ligament: an experimental-numerical analysis. Connect Tissue Res $\underline{45}$ (4-5), 222-230

Nedwed V, Miethke RR (2005): Motivation, acceptance and problems of Invisalign® patients. J Orofac Orthop $\underline{66}, 162-173$.

Oppenheim A (1942): Human tissue response to orthodontic intervention of short and long duration. Am J Orthodont Oral Surg 28, 263-301

Owen AH (2001): Accelerated Invisalign treatment. J Clin Orthod 35(6), 381-385

Owman-Moll P, Kurol J (1998): The early reparative process of orthodontically induced root resorption in adolescents-location and type of tissue. Eur J Orthod 20, 727-732

Owman-Moll P, Kurol J (2000): Root resorption after orthodontic treatment in high - and low - risk patients: analysis of allergy as a possible predisposing factor. Eur J Orthod 22, 657-663

Owman-Moll P, Kurol J, Lundgren D (1996): Effect of doubled orthodontic force magnitude on tooth movement and root resorptions. An inter-individual study in adolescents. Eur $\mathbf{J}$ Orthod $\underline{18}, 141-150$

Pandis N, Eliades T, Partowi S, Bourauel C (2008 a): Forces exerted by conventional and self-ligating brackets during simulated first- and second-order corrections. Am J Orthod Dentofacial Orthop $\underline{133}(5), 738-742$ 
Pandis N, Eliades T, Partowi S, Bourauel C (2008 b): Moments Generated during Simulated Rotational Correction with Self-Ligating and Conventional Brackets. Angle Orthod $\underline{78}$ (6), $1030-1034$

Parker RJ, Harris EF (1998): Directions of orthodontic tooth movements associated with external apical root sorption of the maxillary central incisor. Am J Orthod Dentofac Orthop $\underline{114}, 677-683$

Ponitz RJ (1971): Invisible retainers. Am J Orthod $\underline{59}$ (3), 266-271

Proffit WR: Contemporary Orthodontics. Calif: Mosby, Inc, 3. Auflage, St. Louis 2000, 304

Reitan K (1957): Some factors determining the evaluation of forces in orthodontics. Am J Orthod $\underline{43}, 32-45$

Reitan K (1960): Tissue behavior during orthodontic tooth movement. Am J Orthod $\underline{46}$, 881900

Reitan K (1964): Effects of force magnitude and direction of tooth movement on different alveolar bone types. Angle Orthod 34, 244-255

Reitan K (1967): Clinical and histologic observation on tooth movement during and after orthodontic treatment. Am J Orthod $\underline{53}, 721-745$

Rinchuse DJ, Rinchuse DJ (1997): Active tooth movement with Essix-based appliances. J Clin Orthod $\underline{31}(2), 109-112$

Rosarius N, Friedrich D, Fuhrmann R, Rau G, Diedrich P (1996): Konzept und Entwicklung eines Meßsystems zur in-vivo-Erfassung orthodontisch wirkender Kräfte und Momente bei der Multibandtechnik. J Orofac Orthop/Fortschr Kieferorthop 57, 298-305

Rost D, Schwarze C, Hilgers R (1993): Materialeigenschaften der Werkstoffe für Positioner eine In-vitro-Untersuchung. Fortschr Kieferorthop $\underline{54}$ (2), 71-75 
Rost D, Schwarze CW, Hilgers RD (1995): Die Kraftabgabe von Positionern bei unterschiedlicher Schneidezahnprotrusion. Eine In-vitro-Untersuchung. Fortschr Kieferorthop $\underline{56}(2), 104-109$

Rygh P (1976): Ultrastructural changes in tension zones of rat molar peridontium incident to orthodontic tooth movement. Am J Orthod $\underline{70}$, 269-281

Sameshima GT, Sinclair PM (2001): Predicting and preventing root resorption: Part I. Diagnostic factors. Am J Orthod Dentofac Orthop 119, 505-510

Schmuth G : Kieferorthopädie 2, Praxis der Zahnheilkunde, Band 12. 3. Auflage, Urban \& Schwarzenberg, München 1992, 87

Schopf P: Curriculum Kieferorthopädie, Band I und II; 3. Überarbeitete Auflage. Quintessenz Verlags-GmbH, Berlin 2000

Schroeder HE: The Periodontium. Springer, Berlin 1986

Schwarz AM (1931): Die Gewebeveränderung bei orthodontischen Maßnahmen. Fortschr Orthodont $\underline{1}, 381-407$

Schwarz AM (1932): Die Gewebeveränderung bei orthodontischen Maßnahmen. Fortschr Orthodont $\underline{2}, 11-35$

Sheridan JJ, Ledoux W, McMinn R (1993): Essix Retainers: fabrication and supervision for permanent retention. J Clin Orthod 27 (1), 37-45

Sheridan JJ, Hillard K, Armbruster P: Essix Appliance Technology: Applications, Fabrication and Rationale. GAC International, Inc., Bohemia/NY 2003

Storey E (1973): The nature of tooth movement. Am J Orthod $\underline{63}$, 292-314

Vlaskalic V, Boyd R (2001): Orthodontic treatment of a mildly crowded malocclusion using the Invisalign System. Aust Orthod J 17(1), 41-66 
Vlaskalic V, Boyd RL (2002): Clinical evolution of the Invisalign appliance. J Calif Dent Assoc $\underline{30}$ (10), 769-776

Vlaskalic V, Boyd R, Hordt C, Miethke RR (2001): Die kieferorthopädische Behandlung mit dem Invisalign-System. Kieferorthopädie Sonderheft Invisalign, 17-24

Walker MP, Ries D, Kula K, Ellis M, Fricke B (2007): Mechanical properties and surface characterization of beta titanium and stainless steel orthodontic wire following topical fluoride treatment. Angle Orthod $\underline{77}$ (2), 342-348

Wang T, Zhou G, Tan X, Dong Y (2007): Evaluation of force degradation characteristics of orthodontic latex elastics in vitro and in vivo. Angle Orthod $\underline{77}$ (4), 688-693

Warunek SP, Sorensen SE, Cunat JJ, Green LJ (1989): Physical and mechanical properties of elastomers in orthodontic positioners. Am J Orthod Dentofacial Orthop $\underline{95}$ (5), 388-400

Wong BH (2002): Invisalign A to Z. Am J Orthod Dentofacial Orthop 121 (5), 540-541 


\section{Danksagung}

Ganz besonders möchte ich mich bei meinem Doktorvater Herrn PD Dr. med. dent. Wolfram Hahn für die gute Betreuung und die wertvollen Ratschläge für meine Arbeit bedanken.

Ich danke Herrn Prof. Dr. med. dent. Dietmar Kubein-Meesenburg, Direktor der Abteilung Kieferorthopädie, der diese Arbeit ermöglicht hat.

Außerdem möchte ich mich bei allen Mitarbeitern der Abteilung Kieferorthopädie bedanken, die bei der Studienserie, zu der auch die vorliegende Arbeit gehört, mitgewirkt haben. Mein herzlicher Dank gilt Herrn Dr. med. dent. Benjamin Engelke, dessen Vorarbeit sehr hilfreich für meine Arbeit war.

Weiterhin bedanke ich mich bei den Mitarbeiterinnen der Medizinischen Statistik, Frau Katharina Lange und Frau Antonia Zapf. 